\title{
Surfactant-Templated Zeolites: From Thermodynamics to Direct Observation
}

\section{Monica J. Mendoza-Castro, Elena Serrano, Noemi Linares, * and Javier Garcia-Martinez*}

Surfactant-templating is a versatile method to introduce tailored intracrystalline mesoporosity in zeolites. This method has been proven to be extremely effective to finely control both the amount mesoporosity and the size of their mesopores, while maintaining the main features of the original zeolite, such as crystallinity, acidity, and hydrothermal stability. By building on the knowledge generated during the last $\mathbf{3 0}$ years in the field of amorphous mesoporous materials, the surfactant-templating method has been successfully applied to develop intracrystalline mesoporosity into a variety of zeolite structures including FAU, BEA, MOR, LTL, and MFI. The improvement in both the textural and diffusional properties of the zeolite results in excellent catalytic performances in different industrially relevant processes, ranging from fluid catalytic cracking to the synthesis of active pharmaceutical ingredients. As a result of the excellent catalytic performances shown by the surfactant-templated mesoporous $Y$ zeolite, this is currently being used in several refineries, being the first industrial and large-scale application of hierarchical zeolites. In this progress report, the literature regarding the surfactant-templating method in zeolites is critically reviewed.

\section{Introduction}

Hierarchical zeolites have emerged as an alternative to overcome the mass transport limitations of microporous zeolites, specifically in the catalytic transformation of bulky molecules. ${ }^{[1]}$ Whereas the increased conversion is usually highlighted and attributed to an easier access to the active sites, the elimination-or at least reduction-of undesired secondary reaction, due to long diffusion path lengths is usually overlooked. ${ }^{[2-4]}$ Herein, we provide some illustrative examples of how the development of intracrystalline mesoporosity in zeolites boosts not only its activity but, even more importantly, its selectivity and lifetime. ${ }^{[2,3]}$ Many strategies have been reported in the last years to increase the external surface area of the zeolites and shorten the diffusion path lengths of the reactants in the catalyst crystal, which subsequently enhance their catalytic performance. ${ }^{[5-7]}$

M. J. Mendoza-Castro, Dr. E. Serrano, Dr. N. Linares, Prof. J. Garcia-Martinez Laboratorio de Nanotecnología Molecular

Departamento de Química Inorgánica

Universidad de Alicante

Ctra. San Vicente-Alicante s/n, San Vicente del Raspeig, Alicante

E-03690, Spain

E-mail: noemi.linares@ua.es; j.garcia@ua.es

The ORCID identification number(s) for the author(s) of this article can be found under https://doi.org/10.1002/admi.202001388.

DOI: 10.1002/admi.202001388
These strategies, which include the prepa- 10 ration of nanozeolites, the synthesis of 11 extra-large pore zeolites, and the incorpo- 12 ration of a secondary (and larger) porous 13 system into the crystals, ${ }^{[5,8]}$ among others, 14 have been summarized in a number of 15 excellent review articles. ${ }^{[3,9-15]}$ Among 16 the different strategies developed to over- 17 come the diffusion limitations of zeolites, 18 in 2005, Ying and Garcia-Martinez ${ }^{[16]} 19$ described a postsynthetic method to intro- 20 duce well controlled mesoporosity in fully 21 crystalline zeolites by using surfactants. 22 This method, named either as surfactant- 23 templating or mesostructuring, involves 24 the hydrothermal treatment of the zeolite 25 in a mildly basic cationic surfactant solu- 26 tion (typically alkyltrimethyl ammonium 27 bromide $\left(\mathrm{C}_{n} \mathrm{TAB}\right)$, and $\left.\mathrm{pH}=9-12\right)$ at inter- 28 mediate temperatures $\left(60-150^{\circ} \mathrm{C}\right)$. By this 29 treatment, intracrystalline mesoporosity 30 is developed, whose size and volume can 31 be independently adjusted by using sur- 32 factants of different lengths and by varying the basicity of the 33 solution, respectively (Scheme 1a). ${ }^{[9]}$ The surfactant-templating 34 method should not be mistaken with the so-called recrystalliza- 35 tion techniques. ${ }^{[15,17]}$ The latter involves two steps; first, the par- 36 tial dissolution of the zeolite in a highly basic solution, followed 37 by the surfactant-assisted precipitation of the dissolved species. 38 Even here, the term recrystallization is misleading as these dis- 39 solved species do not recrystallize into a zeolite but precipitate 40 as a diverse amorphous phase. It is important to note that fauja- 41 site with $\mathrm{Si} / \mathrm{Al}$ ratios much higher than 3 cannot be crystallized 42 by direct synthesis. On the contrary, the surfactant-templating 43 method involves the short-scale breaking and reconstruction 44 of bonds needed to accommodate the newly formed intracrys- 45 talline mesoporosity in a process that can be described as the 46 rearrangement of the crystal. ${ }^{[18]}$ In fact, the generation of tun- 47 able mesoporosity in the material occurs while preserving the 48 key properties of the zeolite, such as crystallinity, acidity, and 49 hydrothermal stability. ${ }^{[18]}$ As such, surfactant-templating has 50 arisen as a robust approach to obtain hierarchical zeolites with 51 superior catalytic performances for the transformation of bulky 52 molecules. ${ }^{[11]}$

There are other simpler methods to impart mesoporosity 54 into zeolites, such as demetallation, which are very useful 55 when the control over the mesopore architecture or the pres- 56 ervation of some key properties of the zeolites is not crucial 57 (Scheme 1b). However, in most cases, these features must be 58 maintained in order to ensure a good catalytic performance 59 
a) Surfactant-templating process in zeolites:
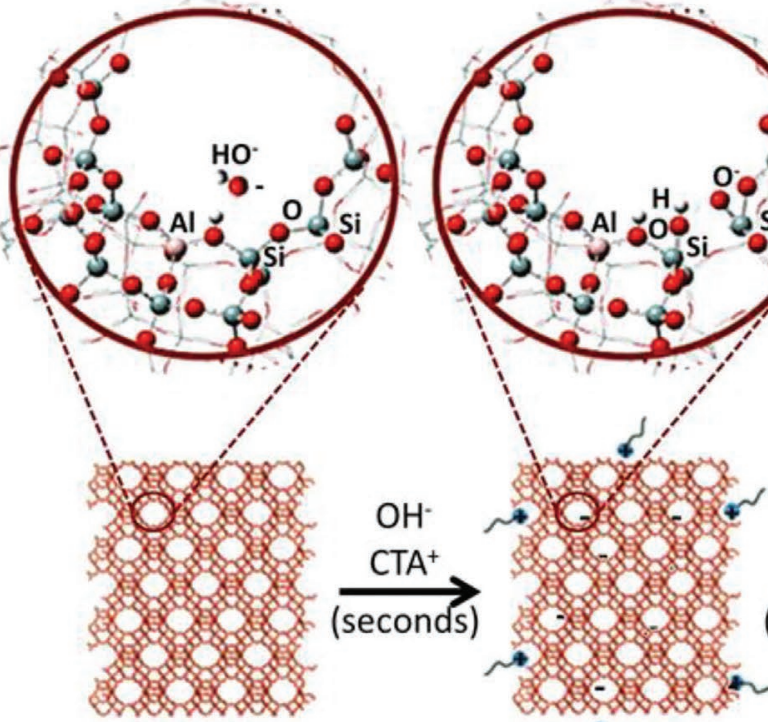

\section{4}

7

b) Differences between desilication and surfactant-templating approaches:
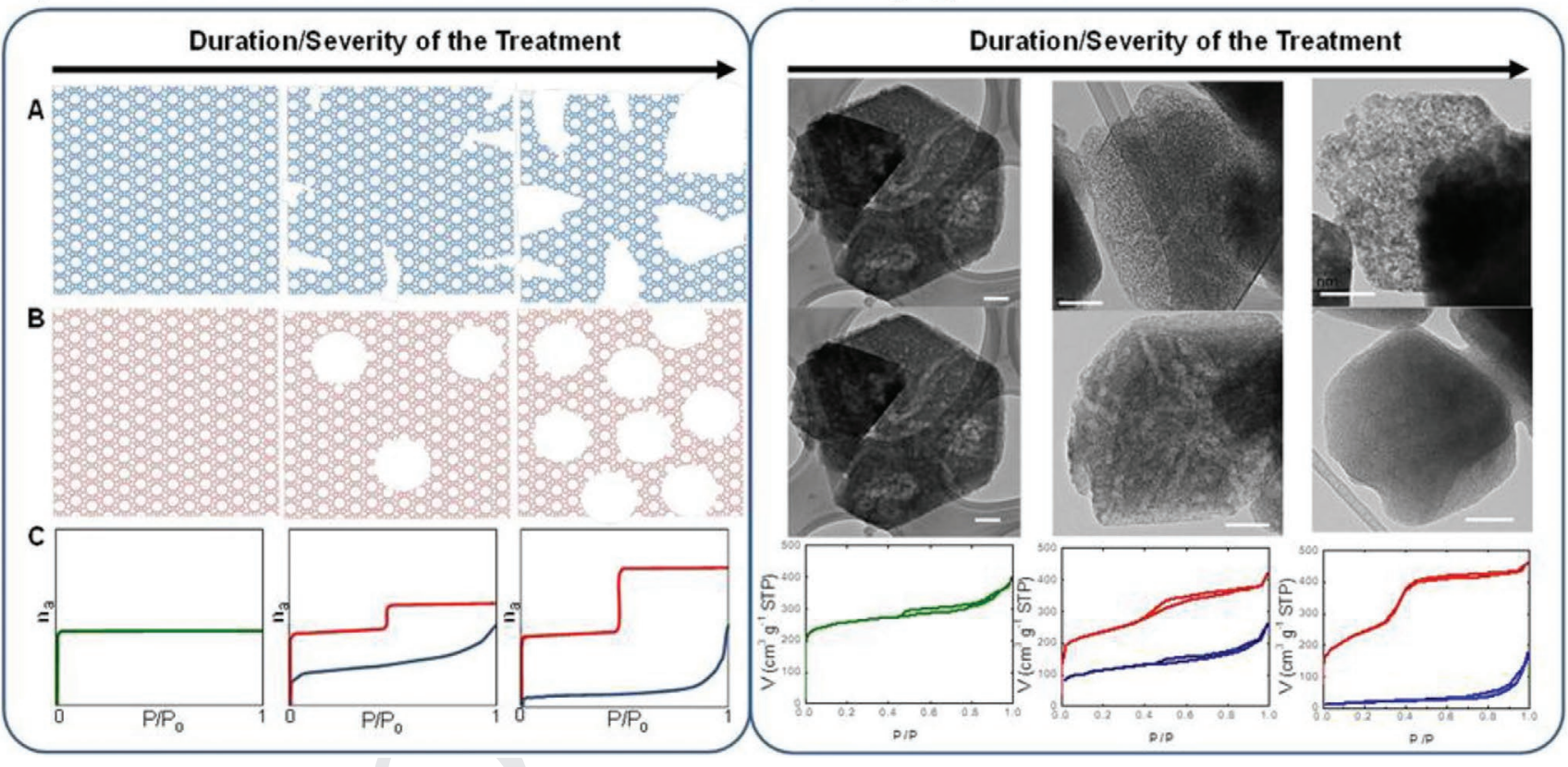

Scheme 1. a) Schematic representation of the different steps involved in the surfactant-templating of zeolites: i) the hydroxyl groups react with the zeolite network to generate negatively charged sites $\left(\mathrm{Si}-\mathrm{O}-\mathrm{Si}+\mathrm{OH}^{-} \rightarrow \mathrm{SiO}^{-}+\mathrm{Si}-\mathrm{OH}\right)$; ii) the cationic surfactant molecules are attracted inside the zeolite by electrostatic interaction; iii) the surfactant molecules self-assemble in micelles inside the zeolite crystals, forming the mesoporosity. Adapted with permission. ${ }^{[20,21]}$ Copyright 2020 and 2014, American Chemical Society. b) Schematic representation (left) and experimental results (right) of the main differences between the two methods used for the generation of mesoporosity in zeolites (in this case, a USY zeolite), namely, desilication and surfactant-templating. A) Structural changes of a zeolite exposed to desilication, and B) surfactant-templating with time or severity of the treatment (basicity of the solution). C) Typical isotherms of a zeolite (green), a desilicated zeolite (blue), and a surfactant-templated zeolite (red). The large mesopores in USY due to steaming are not represented in the scheme for simplicity. Scale bar in TEM images: $100 \mathrm{~nm}$. Reproduced with permission. ${ }^{[18]}$ Copyright 2017, American Chemical Society.

and adequate hydrothermal stability. Then, the use of surfactants, many of which are fairly inexpensive and widely available in large quantities, to develop mesoporosity in zeolites offers many advantages that greatly justify its utilization.

59 Among these benefits, we can cite improved conversion, better selectivity, and extended lifetime of the catalysts, as it will be highlighted with numerous examples in this progress report. We want to emphasize that surfactant-templating builds on the decades of knowledge acquired in the synthesis of well-defined mesoporous materials. ${ }^{[19]}$ The potential of this method and the 
superior properties of these materials are clearly evidenced by the successful commercialization of the mesoporous zeolites obtained through surfactant-templating. ${ }^{[11]}$

In the last years, our group has extensively studied the mechanism of the development of mesoporosity in zeolites by surfactant-templating, paying special attention to i) how these mesopores form and grow inside the crystals, ${ }^{[18]}$ and ii) the thermochemistry of this process, which helped us to understand why this transformation occurs typically under a few hours, even below $180{ }^{\circ} \mathrm{C}$, under very similar conditions than the crystallization of zeolites. ${ }^{[22]}$ Moreover, during many years, and in collaboration with other groups, we have thoroughly investigated the structure of these truly hierarchical materials using a range of advanced techniques. ${ }^{[23]}$ More recently, we have conducted a series of in situ characterization experiments including time-resolved in situ atomic force microscopy (AFM), liquid transmission electronic microscopy (TEM), and in situ synchrotron X-ray diffraction (XRD) to monitor the formation of the mesopores in the zeolite. ${ }^{[2,25]}$ Nowadays, the method has awakened the interest of different groups, which independently have also studied the structure of these hierarchical materials ${ }^{[26,27]}$ and extended the method to a wide range of zeolites. ${ }^{[28-30]}$ In the last years, the number of reports about their use in different applications have multiplied. ${ }^{[11,31-35]}$

In this progress report, we aim at providing an overview of the latest advances in the preparation, characterization, and applications of surfactant-templated zeolites. We have first focused on the importance of fine-tuning the different synthetic parameters to control the development of intracrystalline mesoporosity in zeolites. Then, the hierarchical nature of these materials has been critically reviewed by analyzing the different reports dealing with their advanced and in situ characterization. The thermodynamics and kinetics of the formation of mesoporosity in zeolites by surfactant-templating and their superior properties in different applications have been compared to their microporous counterparts. This report ends with an outlook on the current challenges and future opportunities for this new family of hierarchical catalysts.

\section{Intracrystalline Development of Mesoporosity in Zeolites by Surfactant-Templating}

\subsection{Evaluation of the Treatment Conditions}

The incorporation of mesoporosity in a commercially available USY zeolite (Zeolyst CBV 720, Si/Al = 15) by surfactanttemplating was first reported in 2005. ${ }^{[16,33]}$ García Martinez et al. described the surfactant-templating of a zeolite with high silicon content by treatment with cetyltrimethyl ammonium bromide (CTAB) at mild basic $\mathrm{pH}$ (9-11), using $\mathrm{NH}_{4} \mathrm{OH}$ as a base at $150{ }^{\circ} \mathrm{C}$. Under basic conditions, negatively charged $\mathrm{SiO}^{-}$ sites are formed through the zeolite crystal (Scheme 1a). Subsequently, the positively charged head of cationic surfactants are electrostatically attached to these sites. Once the right concentration of surfactant is achieved inside the crystal, the surfactant molecules self-assemble in micelles, which generate the desired intracrystalline mesoporosity after calcination. This process causes the expansion of the zeolite crystal, as measured by
He pycnometry, to accommodate the micelles inside the zeolite 1 crystal without any significant zeolite leaching (solid recovery 2 yields are always, at any step of the process, close to $100 \%) \cdot{ }^{[18]} 3$ The evolution of the incorporation of mesoporosity inside the 4 zeolites with the time of treatment is evidenced by $\mathrm{N}_{2}$ adsorp- 5 tion (see Figure 1a). The original zeolite displays a type I iso- 6 therm, typical of microporous materials, with a sharp uptake 7 of $\mathrm{N}_{2}$ at low relative pressures. The presence of large porosity 8 produced by steaming (ultrastabilization) is evidenced by the 9 adsorption of $\mathrm{N}_{2}$ at a relative pressure higher than $0.8 .{ }^{[36]}$ As 10 the time of the surfactant-templated treatment increases, the 11 samples present isotherms that could be described as I + IV 12 type, due to the combination of both the original microporosity 13 of the zeolite and the newly created mesoporosity (Figure 1a, 14 left). Indeed, the very distinctive bimodal pore size distribu- 15 tion of surfactant-templated zeolites allows for the determina- 16 tion of both the micropore and mesopore volume directly from 17 the cumulative pore volume obtained by NLDFT, as shown in 18 Figure $3 c$ of ref. [23].

While different reaction conditions can be used for the syn- 20 thesis (base, temperature, $\mathrm{pH}$ ), it is worthy highlighting that 21 the evolution of the porous texture shown here for these spe- 22 cific samples (Figure 1a, right) is similar in all the reported 23 synthesis for surfactant-templating of zeolites. ${ }^{[18,24]}$ Specifically, 24 the mesoporosity rapidly increases at the beginning of the treat- 25 ment reaching a maximum after which, the mesopore volume 26 becomes constant. On the other hand, the microporosity 27 decreases through the process; however, by carefully selecting 28 the treatment conditions, it is possible to preserve most of the 29 initial microporosity, which is highly desirable for their use in 30 catalysis (Figure 1a, right, and isotherms in logarithmic scale). ${ }^{[24]} 31$ In fact, more than $80 \%$ of the original microporosity of the zeo- 32 lite is maintained even when large amounts of mesoporosity are 33 introduced (if the conditions are judicious adjusted). ${ }^{[38]} \quad 34$

The narrow pore size distribution of the newly formed 35 mesopores is due to the use of micelles (whose size is deter- 36 mined by the length of the aliphatic chain) as poregens. In 37 fact, the fine control that can be achieved using the surfactant- 38 templating method (see Figure $1 \mathrm{a}-\mathrm{d}$, center) is a strong evidence 39 of the role of the surfactant as molecular templates. This is very 40 similar to what has been extensively reported about the use 41 of surfactants of different lengths to finely tune the mesopore 42 size of M41S materials; a process widely known as surfactant- 43 templating. As an example, the incorporation of mesoporosity 44 in USY zeolites by using alkyltrimethylammonium surfactants 45 containing aliphatic chains ranging from $C_{12}$ to $C_{22}$ results in 46 hierarchical materials with mesopore sizes varying from 3 to 47 $6 \mathrm{~nm}$. The very narrow pore size distributions (see Figure 1b, 48 center) illustrate the precise control that can be achieved by this 49 method, which affords materials with tailored mesopore size. 50 In fact, pore size of the newly formed mesopores (Figure 1b, 51 right) is directly related to the number of carbons in the ali- 52 phatic chain of the surfactant. ${ }^{[37]}$

Later on, the effect of the amount of base in the incorpora- 54 tion of the mesoporosity was also reported. ${ }^{[18,38]}$ Figure 1c shows 55 how, at a given time, the amount of mesoporosity increases 56 with the initial concentration of base; which determines the 57 amount of mesoporosity that will be developed in the zeolite. 58 Therefore, the mesopore volume in surfactant-templated 59 
a) Evolution of the mesoporosity with the time of treatment:
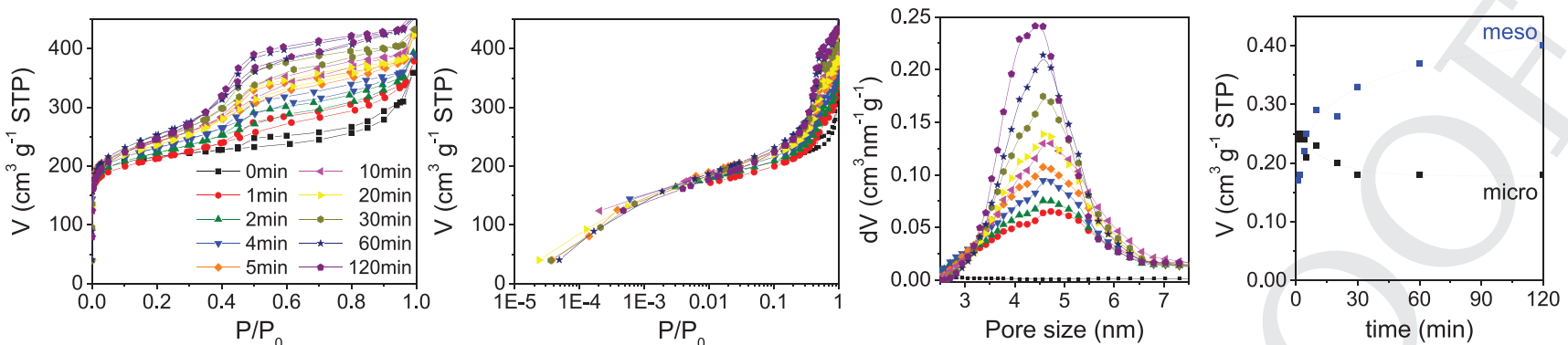

b) Modulation of the mesopore size with CnTAB surfactants of different alkyl chain lenght:
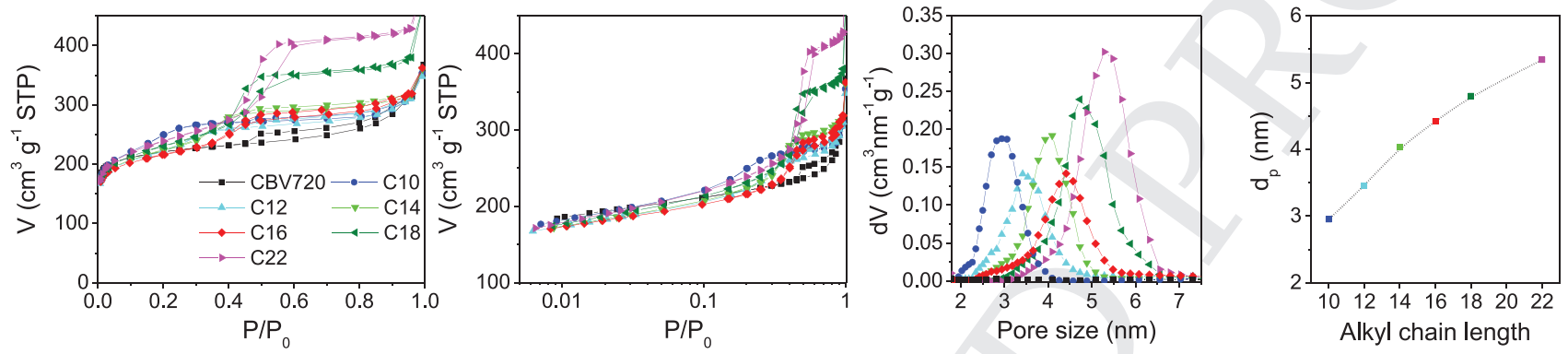

c) Influence of the base concentration:
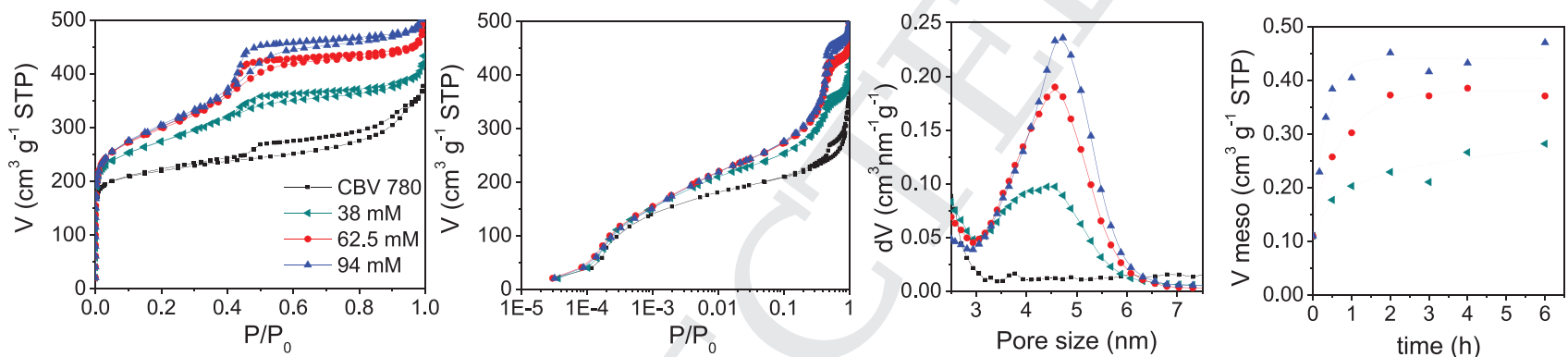

d) Analysis of the hydrothermal temperature:
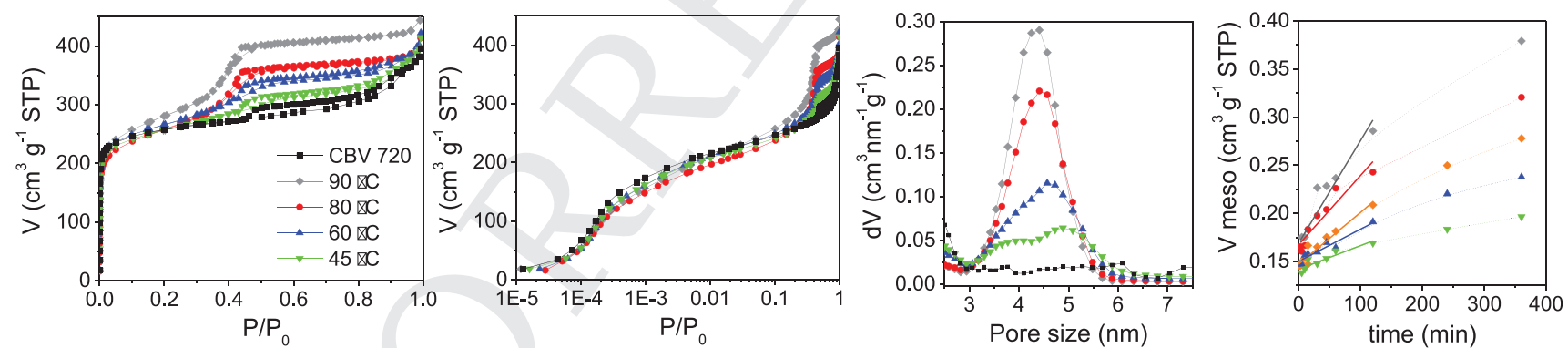

Figure 1. Impact of different treatment conditions during the surfactant-templating of a zeolite $Y$ : a) time of treatment, b) alkyl chain length of the CnTAB surfactant, c) base concentration, and d) hydrothermal temperature, in the porous texture of surfactant-templated zeolites. In every case, the $\mathrm{N}_{2}$ isotherms in linear and logarithmic scale (left), their corresponding pore size distribution (center), and the evolution of the porosity with time (right, a-d) are represented. The right part in (b) corresponds to the evolution of the pore width with the number of carbons in the alkyl chain length of the CnTAB surfactant. a) Adapted with permission. ${ }^{[24]}$ Copyright 2016, American Chemical Society. b) Adapted with permission. ${ }^{[37]}$ Copyright 2020, Royal Society of Chemistry. c) Adapted with permission. ${ }^{[38]}$ Copyright 2019. American Chemical Society. d) Adapted with permission. ${ }^{[25]}$ Copyright 2018, Wiley.

zeolites can be conveniently controlled by adjusting the concentration and strength of the base used during the treatment. The concentration of hydroxyl groups determines the number of $\mathrm{SiO}^{-}$sites formed $\left(\mathrm{Si}-\mathrm{O}-\mathrm{Si}+\mathrm{OH}^{-} \rightarrow \mathrm{SiOH}+\mathrm{SiO}^{-}\right)$. Hence, the more $\mathrm{SiO}^{-}$sites are formed, the more surfactant penetrates in the zeolite and subsequently, higher mesopore volume can be generated. ${ }^{[18,38]}$ This can be clearly observed in Figure 1c (right).
In subsequent studies, the influence of the temperature in the incorporation of mesoporosity in USY by surfactant-templating was analyzed. As shown in Figure 1d, the temperature of the hydrothermal treatment modifies the reaction rate of the process, which proceeds at faster rates at higher temperatures. ${ }^{[25]}$ Moreover, the temperature needed for achieving a certain degree of mesoporosity will be dependent on the strength of 
the base used during the surfactant-templating procedure. The use of weaker bases in the surfactant-templating process, such as $\mathrm{NH}_{4} \mathrm{OH}$, entails higher temperatures of treatment, i.e., $150{ }^{\circ} \mathrm{C}$, to have appreciable reaction rates for the transformation; however, stronger bases ( $\mathrm{MOH}, \mathrm{M}=\mathrm{K}, \mathrm{Na})$ can lead to similar results at lower temperatures $\left(\approx 80^{\circ} \mathrm{C}\right) .{ }^{[18,24,38]}$ The relationship between the $\mathrm{OH}^{-}$and $\mathrm{Si}$ concentrations during the treatment was also independently analyzed by Garlarneau and co-workers using octadecyltrimethylammonium bromide as surfactant for the mesosotructuration. ${ }^{[27]}$ The authors found that the use of higher $\mathrm{OH}^{-} / \mathrm{Si}$ ratios during the surfactanttemplating produces a larger volume of mesoporosity incorporated that, consequently, decreases the micropore volume of the original zeolite. This study concluded that the hierarchical FAU zeolites prepared by surfactant-templating are "a complex family of materials with textural features strongly impacted by the experimental conditions." [27]

Once the parameters that influence the evolution of the surfactant-templating process were evaluated, one could wonder to what extent it is possible to accelerate the introduction of mesoporosity into zeolites by surfactant-templating. Recently, ${ }^{[37]}$ intracrystalline tailored mesoporosity was introduced in USY zeolite by surfactant-templating using a combination of i) high temperatures $\left(150-220^{\circ} \mathrm{C}\right)$, ii) $\mathrm{NaOH}$ as a base, and iii) a tubular reactor with a very high thermal diffusion. These treatment conditions allowed the reduction of the treatment times up to 1 to $5 \mathrm{~min}$, depending of the temperature used. ${ }^{[37]}$ Those findings evidenced the flexibility of the USY zeolite structure to rearrange and accommodate mesopores throughout the whole zeolite crystals in just a few minutes. ${ }^{[37]}$ Moreover, the materials prepared by these ultrafast syntheses exhibit the same trends shown in Figure 1a for the development of mesoporosity and a microporosity similar to more conventional surfactant-templating conditions. All these studies highlight the importance of fine-tuning the different synthetic parameters to obtain optimum materials in which large amounts of mesoporosity can be introduced while preserving most of the microporosity. This is critically important for most applications, as we will discuss in the next sections.

\subsection{Analysis of the Development of the Mesoporosity}

Recently, a detailed study of the different steps involved in the mesopore formation by surfactant-templating of a USY zeolite was published. ${ }^{[18]}$ Samples at different times of reaction were prepared and the evolution of the mesoporosity with the time of treatment was assessed by analyzing the hysteresis loops of the Ar isotherms at $77 \mathrm{~K}$ for the so-formed mesopores (smaller than $4 \mathrm{~nm}$ in size) (Figure 2a). The use of Ar physisorption at $77 \mathrm{~K}$ allows for the determination of how much of each type of mesoporosity (both open and embedded) there is in the zeolite at different times. At short times of treatment, the isotherms feature a $\mathrm{H} 5$ type hysteresis loop, which is a combination of the $\mathrm{H} 1$ and $\mathrm{H} 2$ type-related to, respectively, embedded (partially blocked) and fully accessible (open) mesoporosity (Figure 2a). ${ }^{[39,40]}$ By analyzing the amount of each type of porosity, it was possible to conclude that initially a high percentage of the mesopores are embedded in the zeolite crystal and, consequently, accessible only through the micropores, which points out that the forma- 1 tion of the mesopores begins inside the crystal. By contrast, as 2 the time of treatment increases, these mesopores develop until 3 reaching the exterior of the zeolite, yielding exclusively a H2 4 type hysteresis loop (Figure 2a, right). ${ }^{[18,23]}$ The same conclu- 5 sion was reached in a series of experiments carried out using 6 bulky cationic surfactants. ${ }^{[18,20]}$ Due to the limitation of these 7 surfactants to diffuse through the micropores inside the zeolite 8 crystal, it is not possible to incorporate mesoporosity by sur- 9 factant-templating using bulky molecules, for instance dime- 10 thyldihexadecylammonium bromide $\left(\mathrm{C} 2 \times 16 \mathrm{~A}^{+}\right)$(see Figure $\left.2 \mathrm{~b}\right) .11$ These experiments support that the mesostructuring of the zeo- 12 lite requires that individual surfactant molecules diffuse from 13 the solution mixture to the interior of the crystal where the for- 14 mation of the micelles occurs. ${ }^{[18,20]}$

Although direct surfactant-templating is limited to small- 16 headed and single-chain surfactants, the use of surfactants with 17 different packing parameters (often with bulky heads) could be 18 desirable as they may allow for the formation of novel hierar- 19 chical architectures. ${ }^{[41]}$ Very recently, this limitation has been 20 overcome by carrying out a series of consecutive surfactant- 21 templating treatments. ${ }^{[20]}$ In a first step, a conventional zeo- 22 lite is treated with CTAB to obtain a mesoporous zeolite by 23 surfactant-templating. The newly formed mesoporosity pro- 24 vides enough accessibility to enable the diffusion of bulkier 25 surfactants, in this case $\mathrm{C} 2 \times 16 \mathrm{~A}^{+}$, into the zeolite (Figure 2c) 26 during a second surfactant-templating treatment. In detail, the 27 isotherms and the pore size distributions in Figure 2b,c show 28 that the direct surfactant-templating of the zeolite with $\mathrm{C} 2 \mathrm{x} 16 \mathrm{~A}^{+} 29$ does not generate mesoporosity into the zeolite crystals (golden 30 line) while a second treatment with $\mathrm{C}_{2} \times 16 \mathrm{~A}^{+}$(after the direct 31 surfactant-templating with CTAB) increases the volume of mes- 32 oporosity introduced to the zeolite and its size, which is also 33 evident in the PSD plot (blue line) and in the small-angle XRD 34 pattern of the material (not shown here). ${ }^{[20]}$ This new procedure 35 opens the possibility of incorporating intracrystalline mesopo- 36 rosity into zeolites using a wide range of surfactants.

\subsection{Location and Interconnectivity of the Porosity}

The intracrystalline and homogeneous nature of the surfactant- 42 templating transformation of zeolite crystals, as well as the 43 location and interconnectivity of the developed porosity, has 44 been thoroughly studied by extensive microscopy analyses (see 45 Figure 3). First, the study of ultramicrotomed mesoporous zeo- 46 lites prepared by surfactant-templating (slices of $\approx 80 \mathrm{~nm}$ ) by 47 TEM enabled the observation of the interior of the zeolite crys- 48 tals. The obtained TEM micrographs (Figure 3a) were subse- 49 quently digitalized and analyzed to confirm the intracrystalline 50 and homogeneous nature of the mesoporosity generated by 51 surfactant-templating (Figure 3b-d). Briefly, one squared sec- 52 tion of the micrograph was fast Fourier transformed (FFT; inset 53 Figure 3a) giving, as a result, a pattern showing spots (corre- 54 sponding to the crystalline structure) and an inner halo (which 55 is characteristic of tailored mesoporosity). ${ }^{[18,24]}$ By inverting the 56 FFT pattern of only the spots or only the inner halo (using a 57 mask), the crystal lattice (Figure 3c) and the mesoporous 58 structure (Figure 3d) of the hierarchical zeolite were obtained, 59 
a)
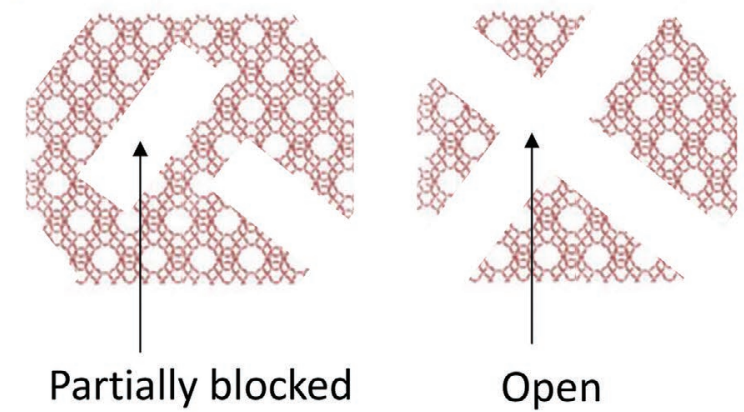

pen
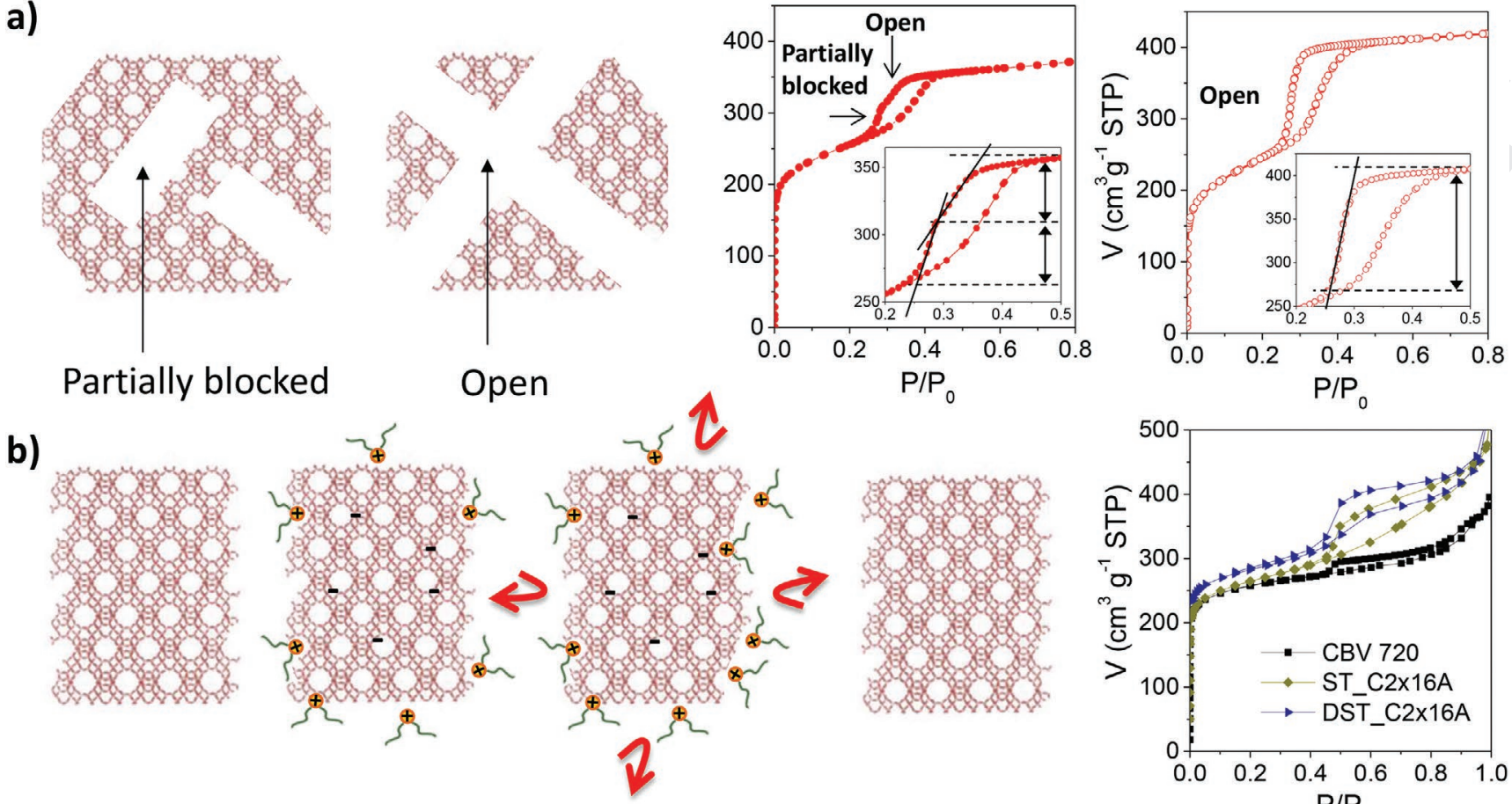

c)
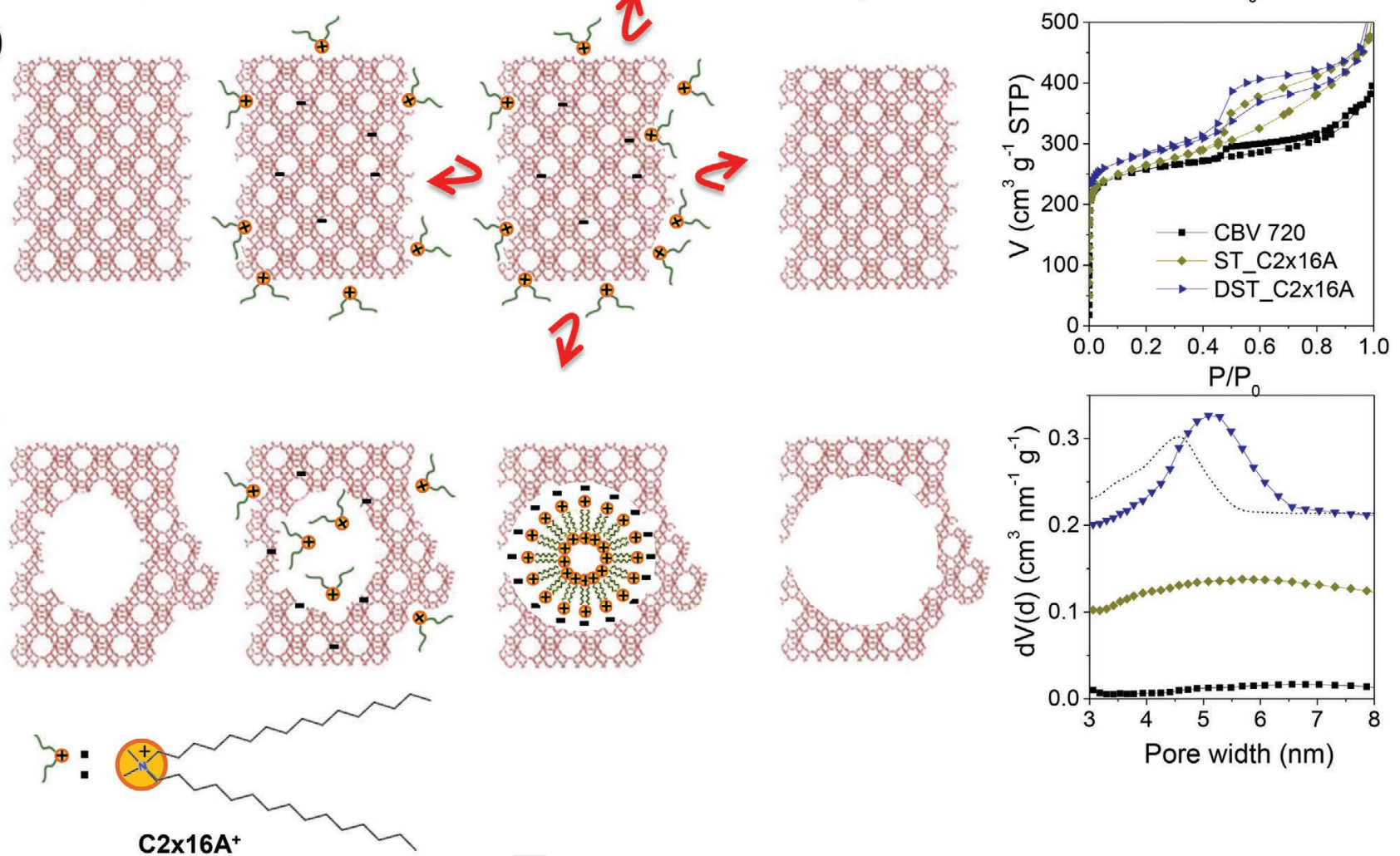

38

Figure 2. a) Evolution of the mesoporosity with the time of treatment was assessed by analyzing the hysteresis loops of the Ar isotherms at $77 \mathrm{~K}$. Reproduced with permission. ${ }^{[18]}$ Copyright 2017, American Chemical Society. b) Schematic representation of the attempt to surfactant template zeolites with surfactants that cannot enter the zeolite and therefore no mesoporosity is formed (ST-C2x16TA in the isotherms of $\mathrm{N}_{2}$ at $77 \mathrm{~K}$ and their corresponding PSD (golden line)). c) Instead, the treatment of a mesoporous zeolite with the same surfactant increases both, the mesopore volume and size of the original mesoporous zeolite (DST-C2x16TA (blue line)). Reproduced with permission. ${ }^{[20]}$ Copyright 2020, American Chemical Society.

respectively. The addition of those images results in a digital replica (Figure 3b), which presents very similar features to the original micrograph. This provides strong evidence of the presence of intracrystalline mesoporosity in surfactant-templated zeolites. ${ }^{[18,24]}$

On the other hand, the connectivity and the 3D distribution of the mesopores in the zeolite was resolved in 2014 by combining 3D electron tomography (3D-ET) and 3D rotation electron diffraction (3D-RED), ${ }^{[23]}$ an advanced characterization procedure developed by Zou and co-workers. ${ }^{[42]}$ This study revealed the 3D hierarchical structure of the surfactant-templated zeolites, allowing for the direct visualization of their structure from the atomic level to the mesoscale (Figure 3e-h). The high crystallinity of the mesostructured zeolites was confirmed by RED obtained from a series of electron diffraction patterns taken at different rotation angles between $\pm 75^{\circ}$ (see a representative ED frame in Figure 3e) from the particle shown in Figure 3f. Subsequently, the 3D reconstruction of the reciprocal lattice (Figure $3 \mathrm{~g}$ ) from the 3D-RED data revealed the existence of two sets of crystal lattices corresponding to the FAU structure, which indicates the presence of twinning. The reconstruction of the electron topographies from the corresponding 3D-ET data provided unprecedented information about the architecture of the pores in the zeolite crystal (Figure 3h), which clearly shows the connectivity of the mesopores through the whole micropore network of the surfactant-templated zeolite. ${ }^{[23]}$

The interconnectivity of the porosity was further analyzed by Garlarneau et al. ${ }^{[2]}$ by using a completely different technique,
1 

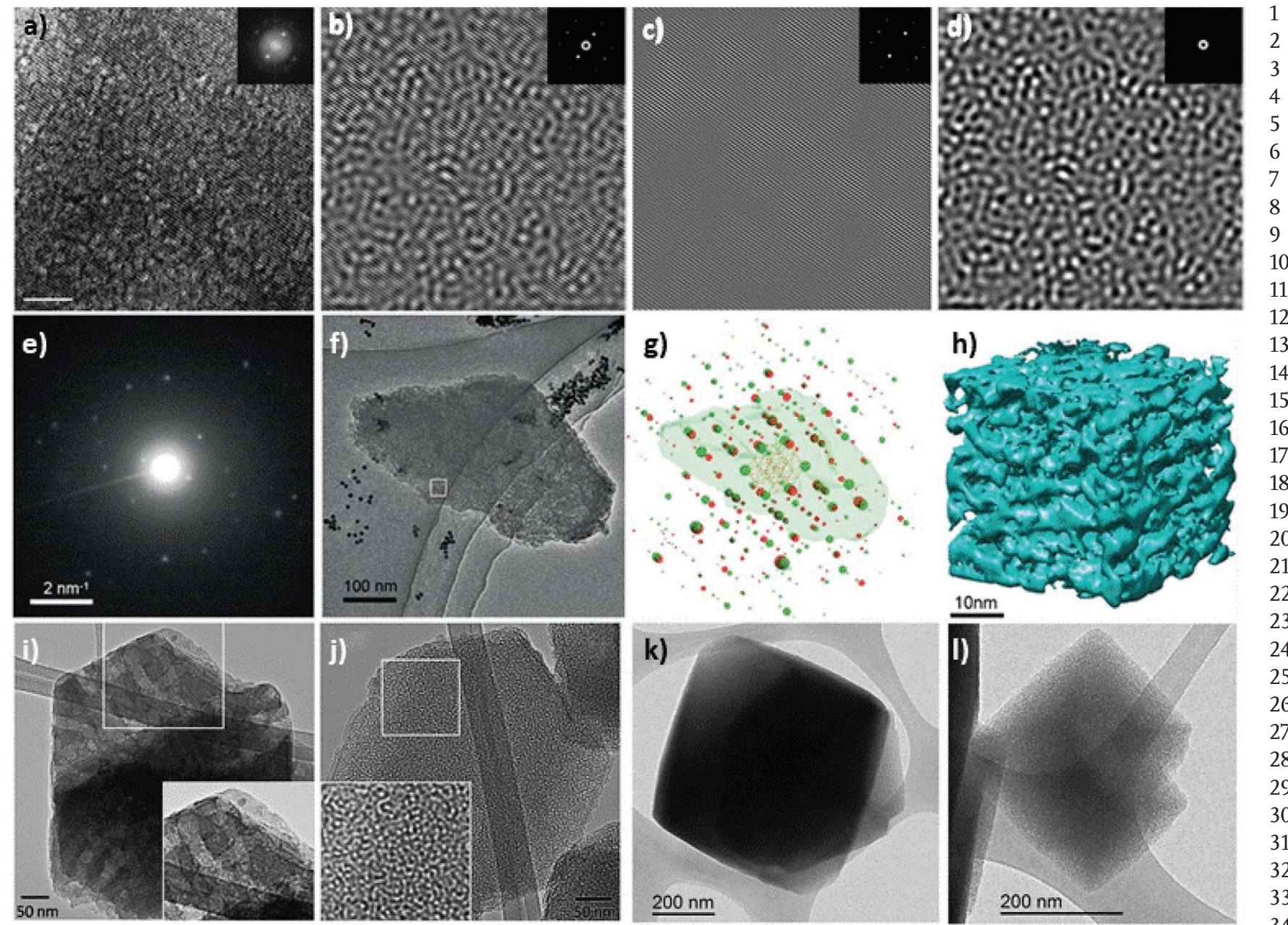

2
3
4
5
6
7
8
9
10
11
12

13

14

Figure 3. a) TEM micrograph of an ultramicrotomed slice $(\approx 80 \mathrm{~nm})$ of a surfactant-templated USY zeolite and inset showing its FFT pattern. The scale bar corresponds to $20 \mathrm{~nm}$. b) Reconstruction of the micrograph showing the presence of both, crystallinity (lattice) and mesoporosity (pale area), within the same slide of surfactant template zeolite. This image was obtained by inversing the FFT pattern shown in (a). c) Reconstruction of the crystalline structure of the surfactant-templating zeolite obtained by inversing the spots of the FFT pattern. d) Reconstruction of the mesopore features obtained from the halo of the FFT pattern. Reproduced with permission. ${ }^{[18]}$ Copyright 2017, American Chemical Society. e-h) Rotation electron diffraction (RED) and electron tomography (ET) analysis: e) an ED frame in the RED data series. f) The corresponding TEM image in the ET series. g) Reconstructed $3 D$ reciprocal lattices from the RED data with the reconstructed 3D morphology of the corresponding particle obtained from ET superimposed. RED data show that the particle is highly crystalline zeolite $Y$ with two twin domains (lattices shown in red and green, respectively) sharing a common [111] axis. h) The 3D volume of a part of the tomogram from the area marked in (f) showing the connectivity of the mesopores in the surfactant-templated zeolite. Reproduced with permission. ${ }^{[23]}$ Copyright 2014, Wiley. TEM images of $\left.i, j\right)$ USY (CBV 720) and k,l) NaY (CBV 100) zeolites i,k) before and j,I) after surfactant-templating. TEM images of the mesoporous zeolites show the uniformly sized and distributed mesopores (lighter spots). Insets in (i) and (j) are magnified views of the white-boxed areas. i,j) Reproduced with permission. ${ }^{[23]}$ Copyright 2014, Wiley. 38 39 . . 列 3 .

this is, pulsed field gradient nuclear magnetic resonance (PFG NMR). PFG NMR is a powerful tool to examine the diffusion of adsorbates in porous materials. In this study, the authors determined the diffusion coefficient of hexane for both the original and the mesoporous zeolites. To rule out the possibility of the formation of a composite material containing a mesoporous amorphous phase (MCM-41 type) and a microporous zeolite after surfactant-templating; they further compared those values with the ones obtained for both a purely mesoporous material, namely, Al-MCM-41, and a physical mixture of Al-MCM-41 and the original FAU (with the same amount of micro- and mesoporosity than the hierarchical material prepared by surfactant-templating). The obtained results provide unambiguous evidence of the one phase nature of the hierarchical FAU, as 47 this material has a higher effective diffusivity than the conven- 48 tional zeolite, but also a lower value than the purely mesoporous 49 material, which proves the interconnectivity between its micro- 50 and mesopores. On the contrary, the diffusion coefficient 51 obtained for the FAU/Al-MCM-41 physical mixture shows two 52 distinct effective diffusion coefficients: i) the contribution of 53 molecules diffusing solely in the microporous and ii) in the 54 mesoporous material, as expected for a composite material. $\quad 55$

Finally, an additional feature was observed by analyzing 56 the TEM micrographs at different treatment times. The com- 57 mercial USY zeolite presents a network of broad and irregular 58 channels due to steaming treatment and acid wash performed 59 

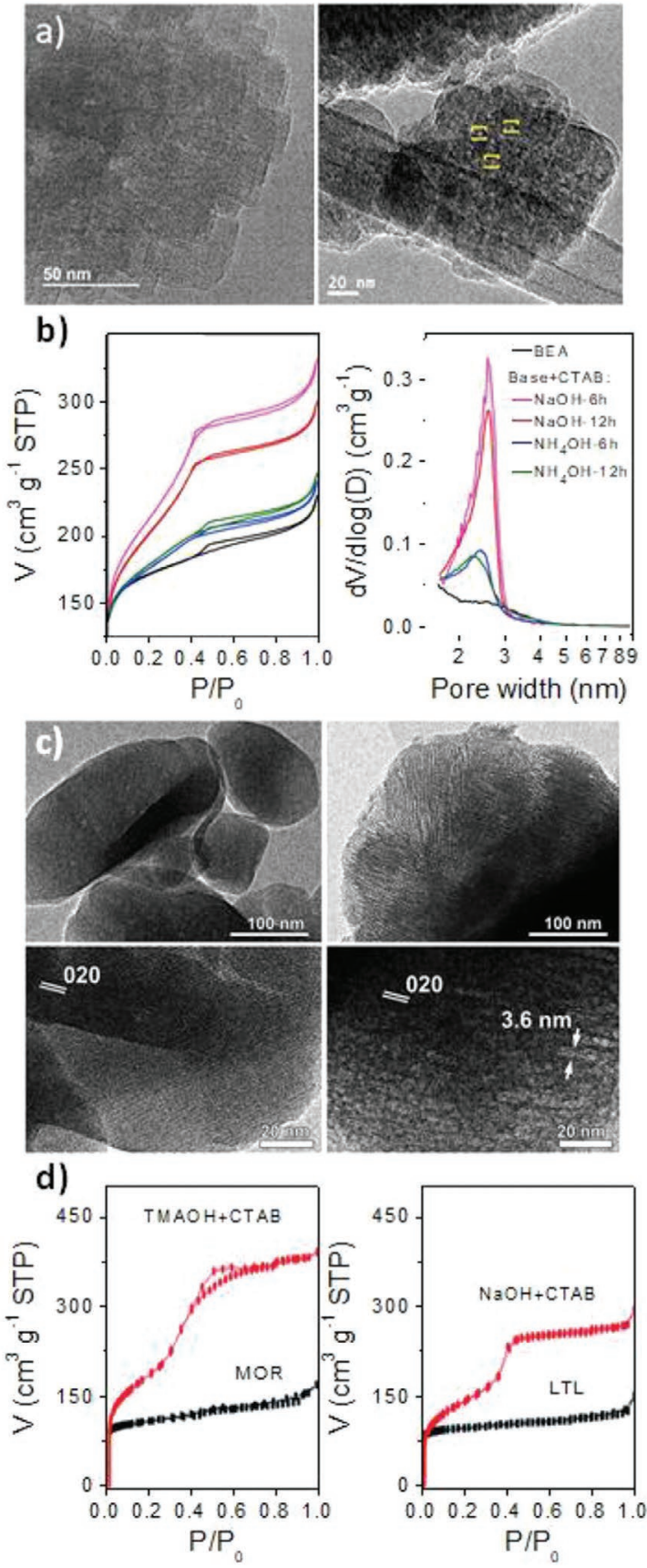

e)

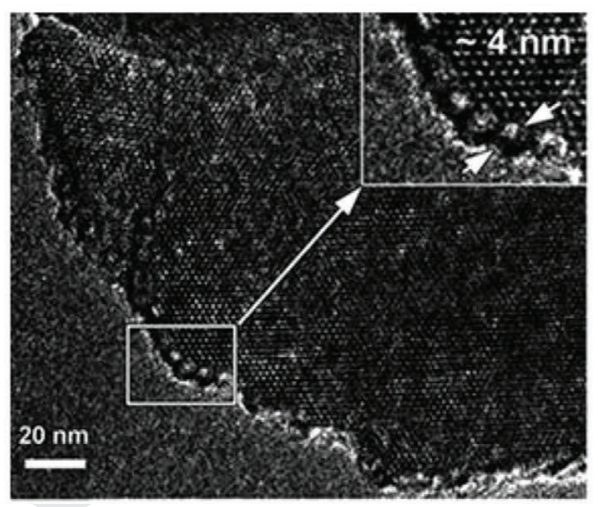

by the supplier (Figure 3i).[36] Once the zeolite is surfactanttemplated with $\mathrm{CTAB}$, the crystal preserves the same shape but its porosity changes drastically, showing only a uniform network of mesopores of $\approx 4-5 \mathrm{~nm}$ throughout the whole crystal (Figure 3j). ${ }^{[23]}$ TEM analysis at intermediate times revealed that, during the process, the channels and large porosity due to the steaming disappear while the surfactant-templated mesoporosity develops.

After this finding, one could wonder if the presence of these large channels was a prerequisite for the surfactant-templating to occur. To answer this question, the incorporation of tailored mesoporosity by surfactant-templating to a $\mathrm{NaY}$ zeolite with high aluminum content, which obviously does not contain the large channels observed in the original USY (Figure 3k), was assessed. ${ }^{[18,33,43]}$ For zeolites with low Si/Al ratio $(\approx 2.5)$, a pretreatment step with mild acid is necessary prior to the surfactant-templating process. This acid pretreatment opens some $\mathrm{Si}-\mathrm{O}-\mathrm{Al}$ bonds at the zeolite, which otherwise could hinder the surfactant-templating as these bonds are more stable than the $\mathrm{Si}-\mathrm{O}-\mathrm{Si}$ in basic media. This strategy allows for the structural rearrangement of the zeolite to incorporate mesoporosity without collapsing their crystalline structure. ${ }^{[18,33,43]}$ As expected, TEM micrographs of the original $\mathrm{NaY}$ zeolite show a dense crystalline structure with a defined crystal shape (see, e.g., Figure 3k). The mesostructured $\mathrm{NaY}$ zeolite presents a much more open structure with intracrystalline mesopores homogeneously distributed throughout the crystal, while maintains the crystal shape of the original zeolite. ${ }^{[43]}$ It is worth noting that the acid pretreatment does not produce any mesoporosity in the zeolite, as confirmed by comparing the $\mathrm{N}_{2}$ isotherms of the original and acid-washed $\mathrm{NaY}$ (see ref. [18]). From these results, it can be concluded that the original large porosity present in USY zeolite is not necessary for the incorporation of mesoporosity by surfactant-templating. In the next section, more examples of the incorporation of mesoporosity in other zeolite structures, which do not present any initial porosity, further corroborate this conclusion.

\subsection{Surfactant-Templating beyond FAU-Type Zeolites}

Several reports have dealt with the incorporation of mesoporosity by the surfactant-templating technique to various zeolitic structures beyond FAU. The reaction conditions in which the mesostructuring of every zeolite takes place should be adjusted differently in order to obtain an optimum material, as it has been abovementioned. Figure 4 summarizes the results obtained by Pérez-Pariente and co-workers, related to the

Figure 4. Effect of surfactant-templating in a,b) BEA, c,d) MOR, and d,e) LTL zeolites. a) TEM images of a beta zeolite (left) before and after (right) the surfactant-templating treatment. b) $\mathrm{N}_{2}$ adsorption analyses of mesoporous beta prepared by using different bases and their corresponding PSD. Reproduced with permission. ${ }^{[29]}$ Copyright 2019, Elsevier. c) TEM images of a mordenite zeolite before (left) and after (right) the surfactant-templating treatment at two different magnifications. d) $\mathrm{N}_{2}$ adsorption isotherms of (left) mesoporous mordenite and (right) LTL prepared by surfactant-templating. e) TEM images of the surfactant-templated LTL. Reproduced with permission. ${ }^{[28]}$ Copyright 2019, Royal Society of Chemistry. 2 3 4 5 6 7 
preparation of mesoporous beta (BEA), ${ }^{[29]}$ as well as by Al-Ani et al., ${ }^{[28,30]}$ which is focused on mordenite (MOR) and zeolite $\mathrm{L}$ (LTL). The incorporation of mesoporosity in a commercial beta zeolite (Zeolyst international, CP814C, with a Si/Al ratio = 19) was carried out using $\mathrm{CTA}^{+}$as surfactant. The analysis of the influence of both the base concentration and the temperature of the hydrothermal treatment on the final properties of this zeolite led to similar conclusions than in previous reports with USY. ${ }^{[29]}$ In Figure 4a, TEM micrographs before (left) and after (right) the treatment of a BEA show the development of substantial intracrystalline mesoporosity (average pore size of $3 \mathrm{~nm}$ ) inside the beta crystals.

The amount of mesoporosity was controlled by using different bases and treatment times, being larger for samples treated with $\mathrm{NaOH}$ solutions due to the stronger basic character of this base in comparison with $\mathrm{NH}_{4} \mathrm{OH}$ (see Figure $4 \mathrm{~b}$ ).

On the other hand, Al-Ani et al. used harsher reaction conditions for de incorporation of mesoporosity in MOR (Zeolyst, CBV 21A, Si/Al = 10) and LTL (Tosoh, HSZ-500KOA, $\mathrm{Si} / \mathrm{Al}=3 \cdot 2) \cdot{ }^{[28,30]}$ In the case of MOR, the incorporation of mesoporosity was obtained by using tetramethylammonium hydroxide as the base (TMAOH) and $\mathrm{CTA}^{+}$as the surfactant.

The reported base concentration $(0.5 \mathrm{M})$ and temperature of the hydrothermal treatment $\left(150{ }^{\circ} \mathrm{C}\right)$ are higher than the ones usually required for the surfactant-templating of USY zeolite $\left(\leq 0.36 \mathrm{M}\right.$ of $\mathrm{NaOH}$ and $\left.\approx 80{ }^{\circ} \mathrm{C}\right)$. The need for harsher conditions for the mesostructuring of this zeolite can be related to the higher framework density of MOR as compared to FAU or BEA, which entails higher stability of this framework toward its transformation. ${ }^{[4,45]}$ On the other hand, similarly to what was described for NaY zeolite, an acid pretreatment (in this case, using sulfuric acid) was needed for the incorporation of mesoporosity in LTL zeolites with high aluminum content (Tosoh, HSZ-500KOA, Si/Al = 3.2). The isotherms of both mesoporous MOR and LTL zeolites show the typical print of the surfactanttemplated mesoporosity as a sharp $\mathrm{N}_{2}$ uptake around $P / P_{0}=0.4$ (Figure 4d). Moreover, while the generated mesopores are clearly located inside the MOR zeolite crystals, the LTL mesopores are mostly located in the exterior layer of the LTL crystal (Figure 4c,e, respectively), which can be due to the $1 \mathrm{D}$ topology of the microporous system in this zeolite. These studies evidence that the surfactant-templating process can be readily applied to largepore zeolites such as, FAU, BEA, MOR, and LTL.

Finally, the surfactant-templating of MFI type zeolites has been reported in a number of articles; ${ }^{[28,30,46]}$ however, the results are quite diverse. One of the most successful approaches is the one recently described by Talebian-Kiakalaieh and Tarighi. Their strategy based on a successful modification of the surfactant-templating method, which produces a threefold increase in the pore volume of the zeolite. ${ }^{[46]}$ In this case, the treatment consists on a desilication and a dealumination step (by first treating the zeolite with a $\mathrm{NaOH}$ solution and subsequently with a diluted $\mathrm{H}_{2} \mathrm{SO}_{4}$ solution both at $80{ }^{\circ} \mathrm{C}$ ). These treatments generate some broad mesoporosity in the zeolite. Finally, the surfactant-templating process was carried out $(0.3 \mathrm{M}$ of $\mathrm{NH}_{4} \mathrm{OH}$ and $\approx 150{ }^{\circ} \mathrm{C}$ ). This hierarchical zeolite was integrated into a fluid catalytic cracking (FCC) catalyst together with a surfactant-templated USY (prepared from a NaY as reported in Section 2.3), yielding enhanced catalytic results for the conversion of vacuum gas oil (VGO) to value-added chemi- 1 cals (particularly gasoline, propylene, and olefins). The discus- 2 sion about the catalytic performance of all hierarchical zeolites 3 can be found in Section 5.2.3.

\section{Advanced In Situ Characterization of the Hierarchical Zeolites}

Different in situ techniques have been used in the last years 10 to characterize the surfactant-templating process. ${ }^{[24,25,38]}$ Four 11 years ago, we reported the first time-resolved study of the 12 development of mesoporosity in zeolites through surfactant- 13 templating by using in situ synchrotron XRD. ${ }^{[24]}$ The formation 14 of mesoporosity was determined by the appearance of a strong 15 peak in the low-angle region of the diffractogram, while the 16 evolution of the zeolite crystallinity was analyzed by monitoring 17 the peaks at higher angles (Figure 5a,b). The intensity of the 18 characteristic peak at low $2 \theta$ angles increased throughout the 19 experiment before reaching a plateau (Figure 5b, red squares), 20 indicating the completion of the surfactant-templating process. 21 This is quite expected since the mesopore volume determined 22 by physisorption experiments evolved similarly. The oppo- 23 site trend was observed for the full width at half-maximum 24 (FWHM) of this peak, which decreases throughout the treat- 25 ment until reaching a constant value (Figure 5b, green trian- 26 gles), showing that the distance between the mesopores evolves 27 during the process toward a constant value. On the other hand, 28 both the micropore volume and the XRD peaks related to the 29 crystallinity of the FAU structure slightly decrease during the 30 treatment (Figure 5b, blue squares). As a reference, when a non- 31 micelling quaternary amine is used instead of $\mathrm{CTA}^{+}$surfactant, 32 no peaks in the small angle region were generated throughout 33 the experiment, which indicates that nonsurfactant amines 34 cannot introduce tailored mesoporosity within the zeolite. ${ }^{[47]} 35$ Nevertheless, the XRD peaks at wide angles (corresponding to 36 the zeolite crystallinity) did not change during the experiment 37 corroborating the protecting role of quaternary amines during 38 basic treatments of zeolites. Hence, it could be inferred that 39 both micelling and nonmicelling quaternary amines protect 40 the zeolite against amorphization, but only those that behave 41 as surfactants can introduce tailored mesoporosity through the 42 mesostructuring of the zeolite. ${ }^{[24]}$

Next, a supercell featuring hexagonally arranged mesoporosity was modeled (Figure 5c) and used to generate the simulated diffractogram shown in Figure $5 \mathrm{~d}$ (left). To build this supercell, the pore size $(4.3 \mathrm{~nm})$ and pore-to-pore distance $(5.1 \mathrm{~nm})$ were obtained by $\mathrm{N}_{2}$ adsorption isotherms at $77 \mathrm{~K}$ and in situ synchrotron XRD, respectively. The theoretical calculations carried out by Castillo and co-workers ${ }^{[2]}$ drew two main conclusions. First, the observed decrease in the intensity of the XRD peaks of the zeolite after surfactant-templating is due to the development of intracrystalline mesoporosity, and not to the 53 formation of an amorphous phase. Second, perfectly ordered 54 hexagonal mesoporosity would result in five reflections in the 55 low angle range (see Figure 5d (left)); however, the experi- 56 mental results exhibit only one XRD peak centered at $2.40^{\circ} 57$ $2 \theta$. This result is consistent with both the presence of small 58 domains of hexagonally (at least partially) ordered mesopores

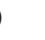
. . (1) 


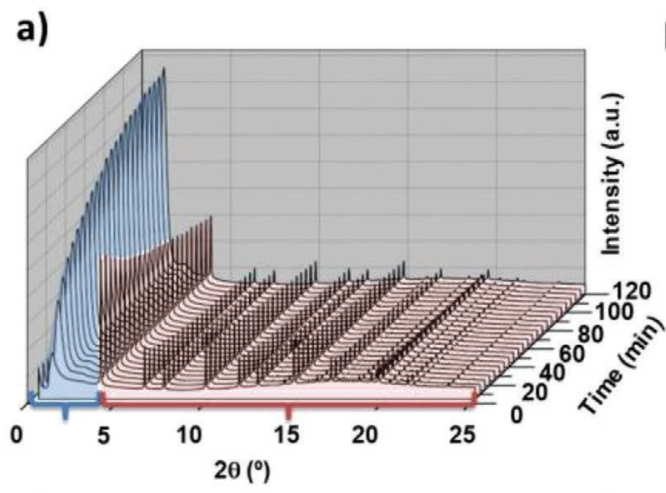

b)

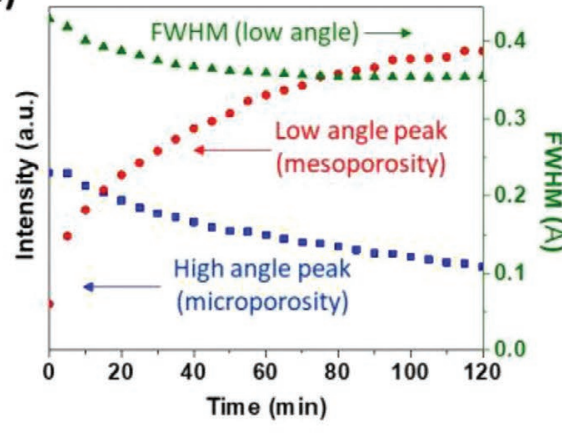

c)

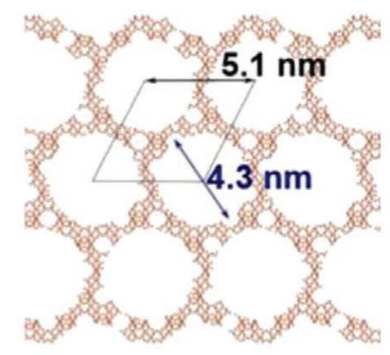

e)
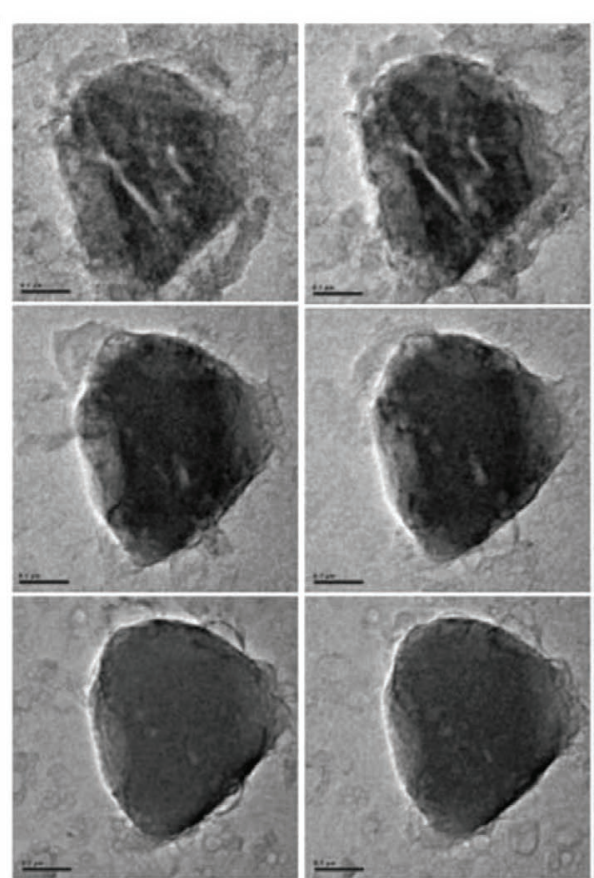

d)

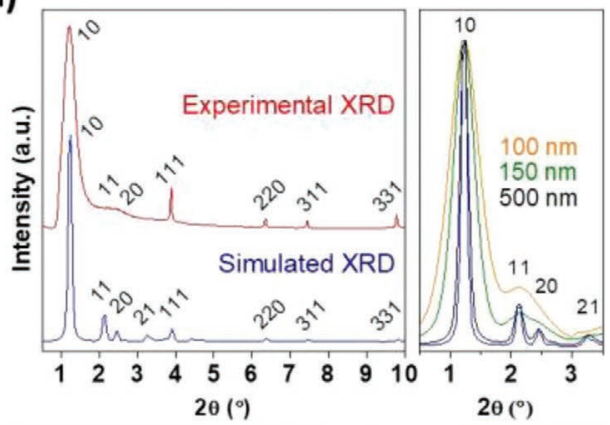

1 2 3 4 5 6 7 8

Figure 5. a-d) In situ time-resolved synchrotron XRD and e) Liq-TEM study of surfactant-templating of USY zeolite at $373 \mathrm{~K}$. a) Time-resolved synchrotron XRD patterns. b) Intensities of the peaks at $2 \theta=1.24^{\circ}$ (red triangles) and $3.84^{\circ}$ (black squares) and d) FWHM values (green triangles) of the low angle peak as a function of time. c,d) Theoretical XRD simulations of the surfactant-templated USY zeolite: c) simulated structure built using the XRD and gas adsorption data. d) Simulated XRD pattern (blue) based on the model shown in (c), experimental (red) XRD patterns of surfactant-templated USY zeolite after 120 min of treatment, and simulated XRD patterns obtained by reducing the ordered mesoporous domain to side lengths of $500 \mathrm{~nm}$ (black), $150 \mathrm{~nm}$ (green), and $100 \mathrm{~nm}$ (orange). e) Digital treatment of frames captured by Liq-TEM during USY zeolite surfactant-templating. Reproduced with permission. ${ }^{[24]}$ Copyright 2016, American Chemical Society.

(see Figure $5 \mathrm{~d}$ (right)) and/or a limited disorder degree into the pore-to-pore distance. ${ }^{[24]}$ It must be also taken into account that, differently to what occurs with the mesoporous M41S materials, the mesopores of the surfactant-templated zeolite are tortuous and not straight, which can also result in broad XRD peaks in the low angle region. 
On the other hand, two advanced microscopic techniques were used to study the morphology evolution in situ during the surfactant-templating process in zeolites. First, the direct observation of individual crystals during the mesostructuring process was carried out by using a liquid cell TEM (Liq-TEM) (Figure 5c). Second, the surface reconstruction of zeolite USY was analyzed by using AFM. ${ }^{[24,38]}$ In the Liq-TEM study, despite the high resolution of the microscope, the analysis of the surfactanttemplating process became challenging because a thick sample composed of both the $\mathrm{NaOH} /$ water and the zeolite should be placed between the two silicon nitride windows of the sealed microcell. This reduces the image resolution, hindering the visualization of features below $5 \mathrm{~nm}$, in this case the mesoporosity.

However, other important changes that occur during the surfactant-templating process could be observed. Specifically, the disappearance of the secondary broad mesoporosity (20-30 nm) of the parent USY zeolite, which is due to the previous steaming treatment (see Section 2), could be studied in detail. For this purpose, real-time videos of the structural transformation during the mesostructuring process of a zeolite were recorded for the first time. Some frames obtained at constant interval times from these movies are shown in Figure 5e. The fraction of void volume in the zeolite was calculated and plotted against reaction time through the digital treatment of those frames. As previously disclosed from ex situ $\mathrm{N}_{2}$ physisorption and TEM experiments, mesostructuring of USY zeolites involves the closing of their broad mesoporosity during the surfactant-templating process. Another conclusion that was drawn from these experiments is that the zeolite crystals maintained their shape during the whole surfactant-templating process and neither amorphous phases nor additional phases were observed during the treatment (see Figure 5e). Finally, control experiments were carried out in the absence of i) base and/or ii) surfactant. The main conclusions that can be drawn from those experiments are that: i) no observable structural changes occur if there is no base; the original broad porosity is therefore preserved, indicating that the surfactant-templating process does not occur in the absence of basic conditions and, ii) the absence of surfactant entails a very rapid degradation and dissolution of the crystal, confirming the role of quaternary amines in preventing the amorphization/dissolution of the zeolite.

In a more recent report, ${ }^{[38]}$ similar results were obtained by using in situ AFM, but in this case, the development of surfactant-templated mesoporosity was systematically observed and analyzed. Moreover, a rapid reconstruction of surface defects during mesostructuring was observed with great resolution (few nanometers) in a time-resolved manner. In fact, numerous defects were found in the surface of USY zeolite, namely, convex protrusions, macrosteps, and concave pits (Figure 6a). The surfactant-templated treatment of the zeolite resulted in the healing of those surface features to render the surfaces more level, as indicated in height profiles obtained at different imaging times (Figure 6a). In order to confirm that the disappearance of those defects was representative of the entire sample, multiple crystal surfaces were analyzed during surfactant-templating treatment and in all cases, more level surfaces with uniformly sized mesopores were observed. At the same time, USY surfaces started to show the presence of surfactant-templated mesopores from the first minutes of exposure to the reaction mixture. High-resolution AFM images 1 of the USY crystal surfaces at the end of the process revealed 2 a homogenous distribution of mesopores, whose size is con- 3 sistent with the PSD obtained from $\mathrm{N}_{2}$ physisorption and TEM 4 (Figure 6b). The use of additional ex situ techniques such as 5 $\mathrm{N}_{2}$ adsorption, TEM of ultramicrotomed samples, powder XRD, 6 and ${ }^{27} \mathrm{Al} \mathrm{NMR}$ further confirmed that the surface phenomena 7 observed by AFM is consistent with changes occurring 8 throughout the entire crystal.

\section{Thermodynamic and Kinetic Studies}

Many aspects related to the thermodynamics of microporous 14 and mesoporous inorganic materials have been extensively 15 studied over the last 10 years, including their synthesis, inter- 16 conversion, and transformations. Navrotsky et al. have greatly 17 contributed to this field by the use of high-temperature oxide 18 melt solution calorimetry. ${ }^{[45]}$ More specifically, they found 19 a good linear correlation between the calculated enthalpy 20 of transformation of different zeolitic structures, related to 21 quartz, and the framework density of those structures, as 22 shown in Figure 7a. Piccione et al. ${ }^{[44]}$ explained this trend in 23 terms of the "quality of packing," this is, denser structures 24 require more energy to be destabilized. More specifically, the 25 presence of "void volumes" determines the number of desta- 26 bilized Si atoms, which have an energetic cost. Hence, as the 27 denser frameworks have fewer void volumes, they are conse- 28 quently more stable structures. ${ }^{[44,48]}$ On this matter, zeolitic 29 materials are only between 6.8 and $14.4 \mathrm{~kJ} \mathrm{~mol}^{-1}$ less stable 30 than quartz (Figure 7a). In other words, zeolite frameworks 31 are metastable with respect to denser phases, and the energy 32 needed for their phase transformation is $\approx 8 \mathrm{~kJ} \mathrm{~mol}^{-1}$, which is 33 only twice the thermal energy required for the typical synthesis 34 of a zeolite at $373 \mathrm{~K}\left(\approx 6.2 \mathrm{~kJ} \mathrm{~mol}^{-1}\right) \cdot{ }^{[44]}$ Through the judicious 35 selection of organic structure-directing agents, which stabilize 36 one structure over others by quite small stabilization ener- 37 gies $\left(<6 \mathrm{~kJ} \mathrm{~mol}^{-1}\right.$; Figure $\left.7 \mathrm{~b}\right),{ }^{[45]}$ it is thus possible to selectively 38 obtain one particular structure. ${ }^{[4]}$ Later on, Navrotsky et al. ${ }^{[45]} 39$ related the relative enthalpies of zeolite frameworks with molar 40 volume, with the aim of covering structures without a regularly 41 repeating framework, namely, amorphous mesoporous mate- 42 rials (see Figure 7c). They found that the enthalpies of forma- 43 tion of zeolitic silicas, aluminophosphates, and other zeotype 44 structures increase roughly linearly with molar volume up to 45 $30 \mathrm{~kJ} \mathrm{~mol}^{-1}$; after this point, there is a plateau in the enthalpy 46 of formation for all the mesoporous materials for which the 47 increase in molar volume does not entail an increase in their 48 enthalpy of formation (Figure 7c).

Recently, Linares et al. ${ }^{[22]}$ determined the enthalpy of forma- 50 tion of the commercial USY (CBV 780), both before and after sur- 51 factant-templating, which follow the curve of porous inorganic 52 solids obtained from Navrotsky's findings (Figure 7c). Specifi- 53 cally, by using the enthalpies of solution deduced from calorim- 54 etry $\left(\Delta H_{\mathrm{ds}}\right)$ and the thermodynamic cycle presented in Table 1, 55 the enthalpies of formation calculated for the original USY (CBV 56 780 ) and the corresponding surfactant-templated zeolite were 57 found to be $27.69 \pm 0.95$ and $29.63 \pm 0.99 \mathrm{~kJ} \mathrm{~mol}^{-1}$, respectively. ${ }^{[22]} 58$ As observed in Figure 7c, those are intermediate values between

\section{.} 18 . 
a)
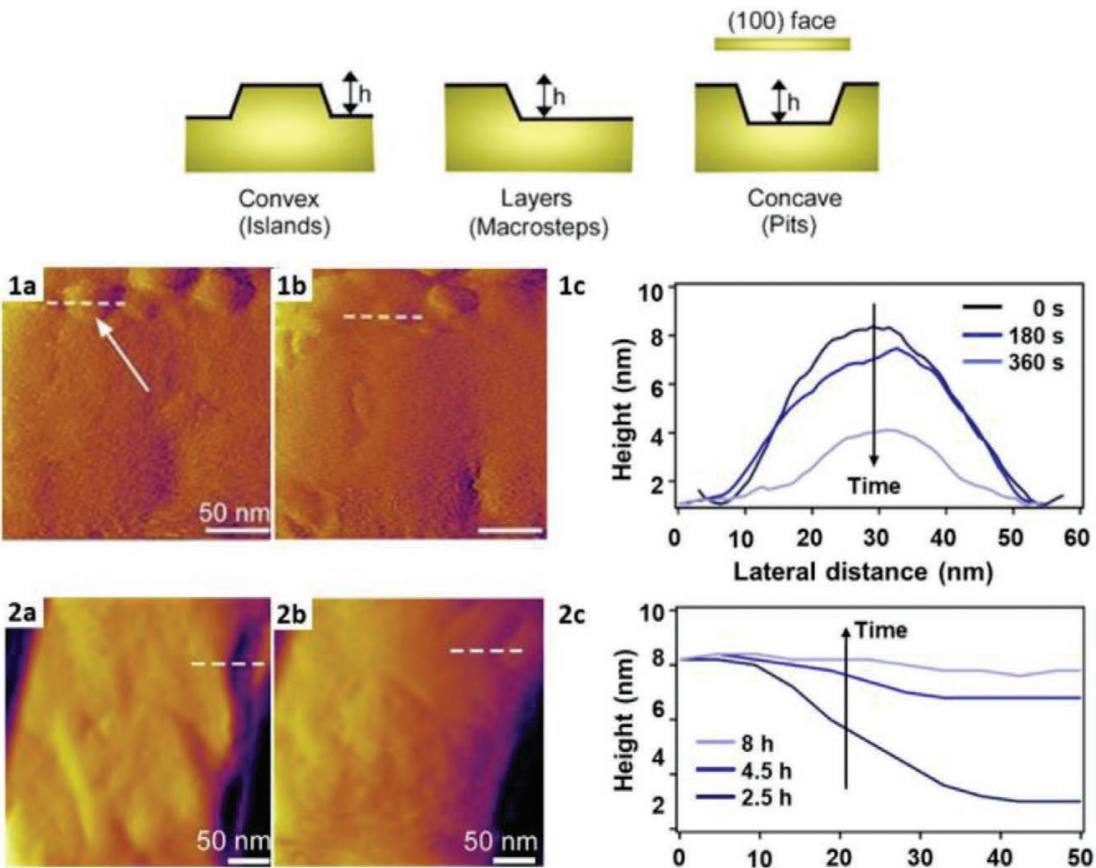

2c
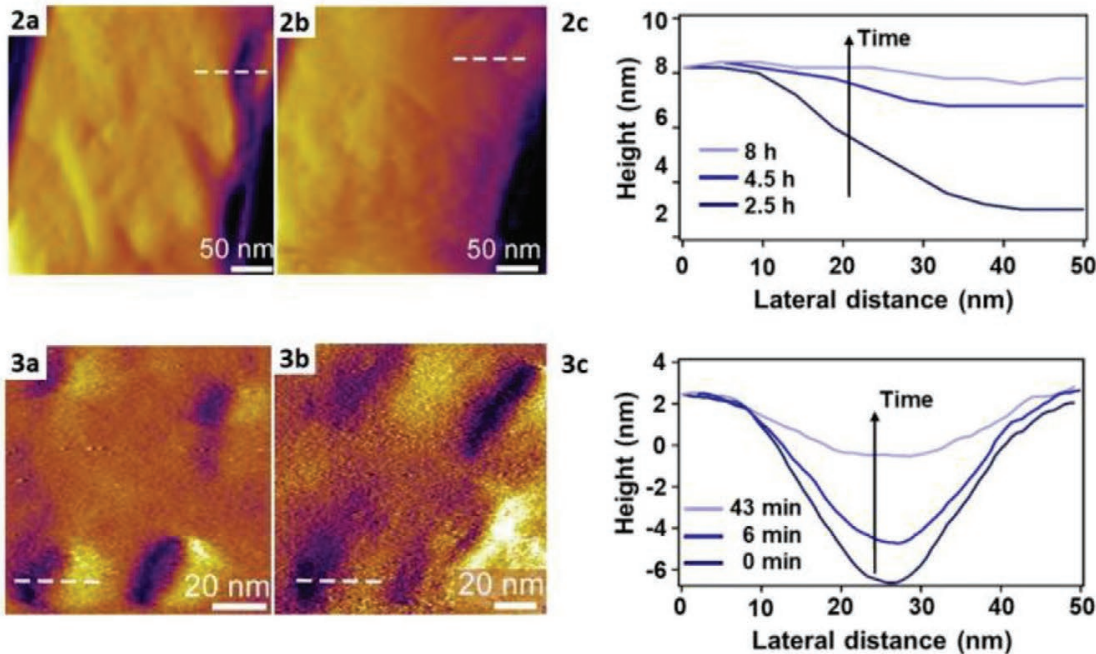

b)
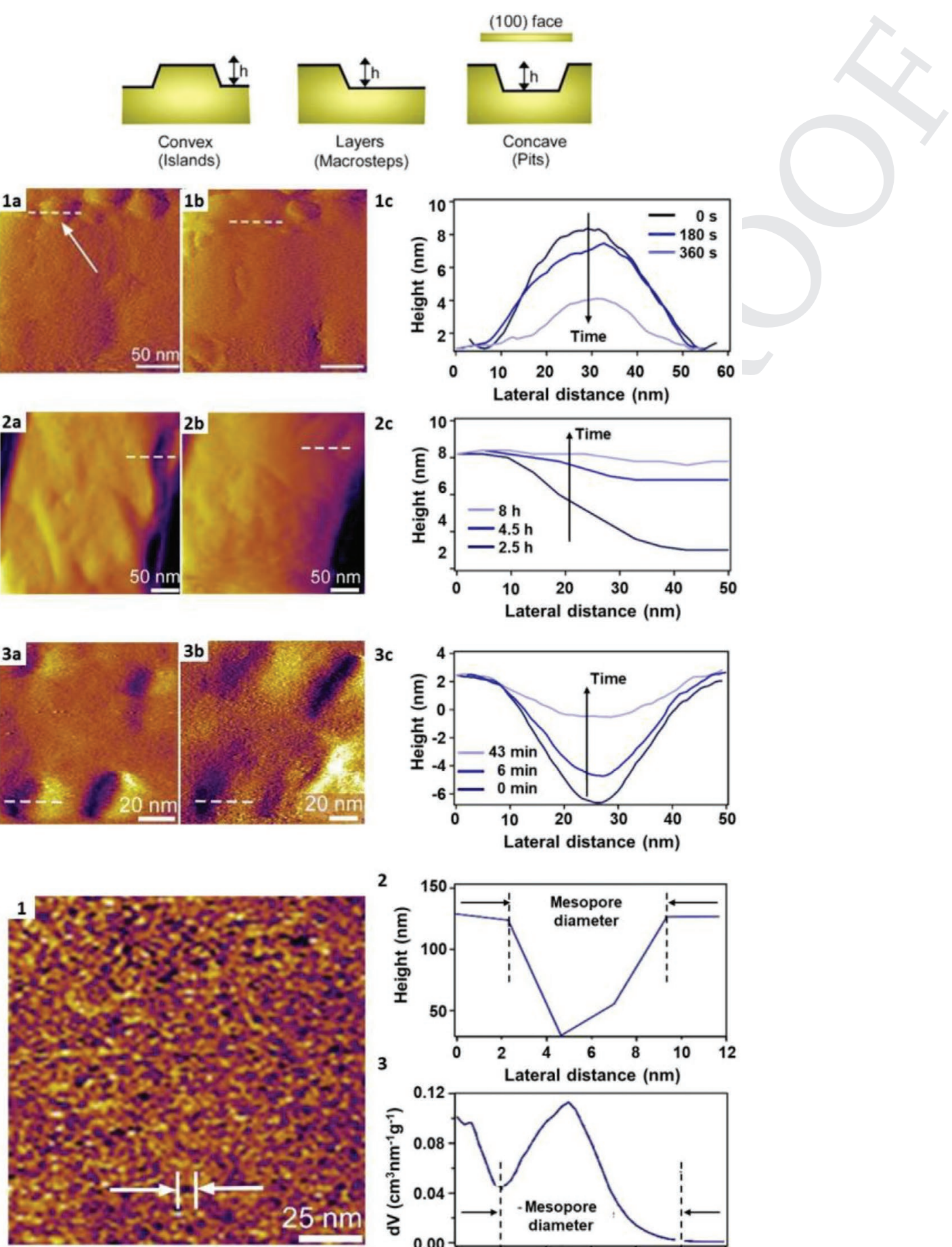

2

3

4

5

6

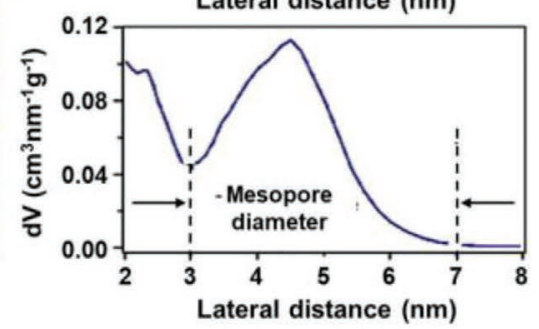

Figure 6. a,b) In situ AFM study during surfactant-templating of USY zeolite at RT. a) Idealized schematics of three types of surface defects analyzed by in situ AFM: convex protrusions, macrosteps, and concave pits. 1a,b) Snapshots from the corresponding movie showing temporal changes of the same USY crystal surface after $4 \mathrm{~h}$ and c) the corresponding height profiles. 2) AFM amplitude mode images show the presence of a) an initial macrostep (white dashed line) and b) the same area after $8 \mathrm{~h}$, and c) height profiles along the white dashed lines at various imaging times showing a reduction in macrostep height. 3) Measurements of a separate USY crystal showing the presence of etch pits on a) an initial surface and b) the same area after $1 \mathrm{~h}$ of treatment of the solution at RT. Etch pits evolve from circular to ellipsoidal shapes with increasing treatment time. 3c) The corresponding height profiles. b-1) High-resolution AFM amplitude mode image showing the uniform distribution of mesopores after 60 min of treatment in solution at RT, 2) the height profile of the feature denoted in panel (1) with the double white arrow, showing the diameter of a representative mesopore, and 3) NL-DFT 

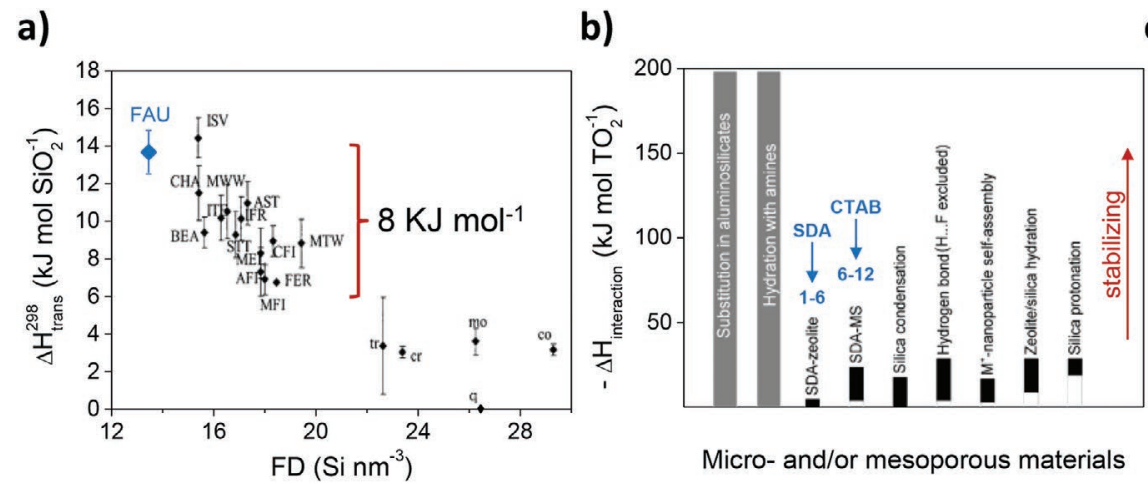

c)

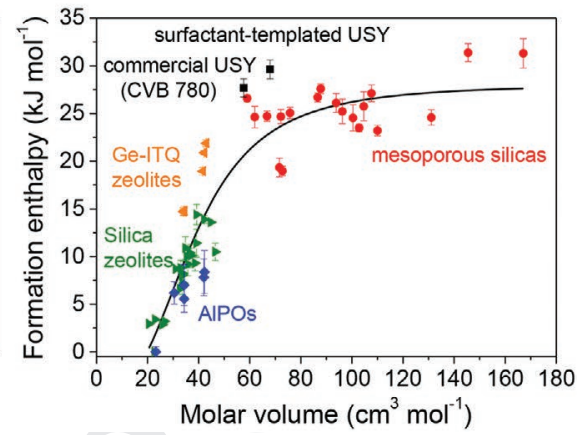

Figure 7. a) Enthalpy of formation versus framework density (FD). Adapted with permission. ${ }^{[44]}$ Copyright 2000, American Chemical Society. b) Enthal- 14 pies of interactions involved in the synthesis of microporous and mesoporous materials. Bands show the range of interaction enthalpies. Reproduced 15 with permission. ${ }^{[45]}$ Copyright 2009, American Chemical Society. c) Enthalpies of formation of the original USY (CBV 780) and the surfactant-templated 16 zeolite regarding other porous materials, as a function of molar volume. The molar volume was calculated by adding the mesoporous volume to the 17 molar volume of the faujasite structure. The rest of the data was taken from ref. [45]. Adapted with permission. ${ }^{[22]}$ Copyright 2019, Wiley-VCH. Adapted 18 with permission. ${ }^{[45]}$ Copyright 2009, American Chemical Society.

1

2

3

4

5

6

7

8

9

10

11

12

13 (6) . 19

the ones corresponding to microporous zeolites (and zeotypes) and the mesoporous silica materials, which is consistent with the hierarchical zeolites being an intermediate material containing the two types of porosity. ${ }^{[45]}$ The presence of a significant amount of large porosity (Figure $3 i$ ) and defects in the original USY zeolite may also explain its location close to the mesoporous silicas. Moreover, the as-determined enthalpies of formation indicate that the surfactant-templated zeolite (after the surfactant removal) is destabilized by only $1.94 \pm 1.69 \mathrm{~kJ} \mathrm{~mol}^{-1}$ relative to the commercial USY zeolite (CBV 780). This value is consistent with the theoretical calculations regarding the increase in the enthalpy of formation caused by the rise in the surface area produced by the surfactant-templating treatment, which is $1.2 \mathrm{~kJ} \mathrm{~mol}^{-1}$. $^{[49]}$ As abovementioned, the organic directing agents play a key role in the stabilization of one zeolitic structure over the others. Similarly, the surfactant drives the formation of mesoporosity by providing enough energy to the system to compensate for the increase in the surface area. As shown in Figure 7b, the CTABmesoporous-silica interactions result in an exothermic stabilizing energy range from 6.00 to $12.00 \mathrm{~kJ} \mathrm{~mol}^{-1}$, depending on the packing of the CTAB. ${ }^{[50]}$ These values are significantly higher than those of their destabilization due to the increase in surface area $\left(1.2 \mathrm{~kJ} \mathrm{~mol}^{-1}\right)$, which explains why surfactant-templating is a thermodynamically favorable process.

Table 1. Thermochemical cycle for USY zeolite and its surfactant-templated counterpart. Reproduced with permission. ${ }^{[22]}$ Copyright 2019, Wiley-VCH.

\begin{tabular}{|c|c|}
\hline Reactions & Enthalpy $\left[\mathrm{KJ} \mathrm{mol}{ }^{-1}\right]$ \\
\hline $\begin{array}{l}\mathrm{Si}_{x} \mathrm{Al}_{(1-x)} \mathrm{H}_{(1-x)} \mathrm{O}_{2} \cdot n \mathrm{H}_{2} \mathrm{O}_{(\mathrm{s}, 298 \mathrm{~K})} \rightarrow x \mathrm{SiO}_{2 \text { (diss, } 975 \mathrm{~K})}+ \\
\left.(1-x) / 2 \mathrm{Al}_{2} \mathrm{O}_{3} \text { (diss, } 975 \mathrm{~K}\right) \\
(1-x) / 2 \mathrm{H}_{2} \mathrm{O}_{(\mathrm{g}, 975 \mathrm{~K})}+ \\
n \mathrm{H}_{2} \mathrm{O}_{(\text {diss, } 975 \mathrm{~K})}\end{array}$ & $\Delta H_{1}=\Delta H_{\mathrm{ds}, 975 \mathrm{~K}}$ \\
\hline $\mathrm{SiO}_{2(\mathrm{~s}, 298 \mathrm{~K})} \rightarrow \mathrm{SiO}_{2 \text { (diss, } 975 \mathrm{~K})}$ & $\Delta H_{2}=\Delta H_{\mathrm{ds}(\mathrm{SiO} 2)}=39.13 \pm 0.32$ \\
\hline $\mathrm{Al}_{2} \mathrm{O}_{3}(\mathrm{~s}, 298 \mathrm{~K}) \rightarrow \mathrm{Al}_{2} \mathrm{O}_{3}$ (diss, $975 \mathrm{~K}$ ) & $\Delta H_{3}=\Delta H_{\mathrm{ds}(\mathrm{Al} 2 \mathrm{O} 3)}=107.93 \pm 0.98$ \\
\hline $\mathrm{H}_{2} \mathrm{O}_{(\mathrm{s}, 298 \mathrm{~K})} \rightarrow \mathrm{H}_{2} \mathrm{O}_{(\mathrm{g}, 975 \mathrm{~K})}$ & $\Delta H_{4}=\Delta H_{\mathrm{ds}(\mathrm{H} 2 \mathrm{O})}=68.98 \pm 0.1$ \\
\hline \multicolumn{2}{|c|}{$\begin{array}{l}\left.x \mathrm{SiO}_{2 \text { (diss, } 975 \mathrm{~K})}+(1-x) / 2 \mathrm{Al}_{2} \mathrm{O}_{3} \text { (diss, } 975 \mathrm{~K}\right) \\
\mathrm{Al}_{(1-x)}+(1-x) / 2 \mathrm{H}_{2} \mathrm{O}_{(1-x)} \mathrm{O}_{2} \cdot n \mathrm{H}_{2} \mathrm{O}_{(\mathrm{s}, 298 \mathrm{~K})}\end{array}$} \\
\hline
\end{tabular}

The determination of the kinetic parameters involved in the 21 surfactant-templating process provided a deeper understanding 22 of this approach and shed new light on its possible mechanism. 23 For this purpose, the reaction rates and the apparent activa- 24 tion energy of the surfactant-templating process were deter- 25 mined in a subsequent study (Figure 8). ${ }^{[25]}$ The original USY 26 zeolite (CBV 720) was treated at different temperatures and in 27 situ analyzed by synchrotron XRD and small-angle X-ray scat- 28 tering (SAXS), while the $\mathrm{pH}$ and temperature evolution were 29 recorded during the whole process, using an experimental 30 setup specifically designed and built to be used in a synchro- 31 tron line, see the description of the apparatus in ref. [25]. The 32 low angle diffractograms recorded every $2 \mathrm{~min}$ at $90{ }^{\circ} \mathrm{C}$ are 33 shown in Figure 8a. The increase in the intensity of the peak 34 at $1.6^{\circ} 2 \theta$ with the time of treatment was used to monitor the 35 development of intracrystalline mesoporosity (Figure 8e). In 36 order to independently assess the rate constants, the evolution 37 of the mesoporosity was also followed by ex situ $\mathrm{N}_{2}$ physisorp- 38 tion at $77 \mathrm{~K}$ (not shown here). Both approaches, XRD and $\mathrm{N}_{2} 39$ physisorption, were used to obtain the corresponding Arrhe- 40 nius plots (Figure 8f, black and green lines, respectively) and 41 their slopes were thus employed to calculate the apparent acti- 42 vation energy of the mesoporosity incorporation in the zeolite. 43 By using the intensity of the peak at $1.6^{\circ} 2 \theta$, the obtained value 44 was $\mathrm{Ea}^{\text {Imeso }}=45 \mathrm{~kJ} \mathrm{~mol}^{-1}$, and from the mesopore volume a 45 $\mathrm{Ea}^{\text {Vmeso }}=43 \mathrm{~kJ} \mathrm{~mol}^{-1}$ was calculated. ${ }^{[25]}$ The similarity between 46 those values, obtained by totally different techniques, corrobo- 47 rated the validity of the results. Moreover, these values are in 48 good agreement with the activation energy of crystallization of 49 zeolites $49-65 \mathrm{~kJ} \mathrm{~mol}^{-1}$. [51] These results confirmed that USY 50 zeolite mesostructuring is energetically viable under the typical 51 conditions, in terms of time and temperature requirements, of 52 zeolites synthesis and interconversions. ${ }^{[22,45]}$ At the same time, 53 the apparent activation energies of the intermediate steps of 54 the surfactant-templating process were also determined. The 55 process involves two intermediate steps: i) the opening of the 56 $\mathrm{Si}-\mathrm{O}-\mathrm{Si}$ bonds, which depends on the $\mathrm{OH}^{-}$concentration ${ }^{[52]} 57$ and; ii) the incorporation of the surfactant. The first step was 58 studied by continuously monitoring the $\mathrm{pH}$ at the different 59 

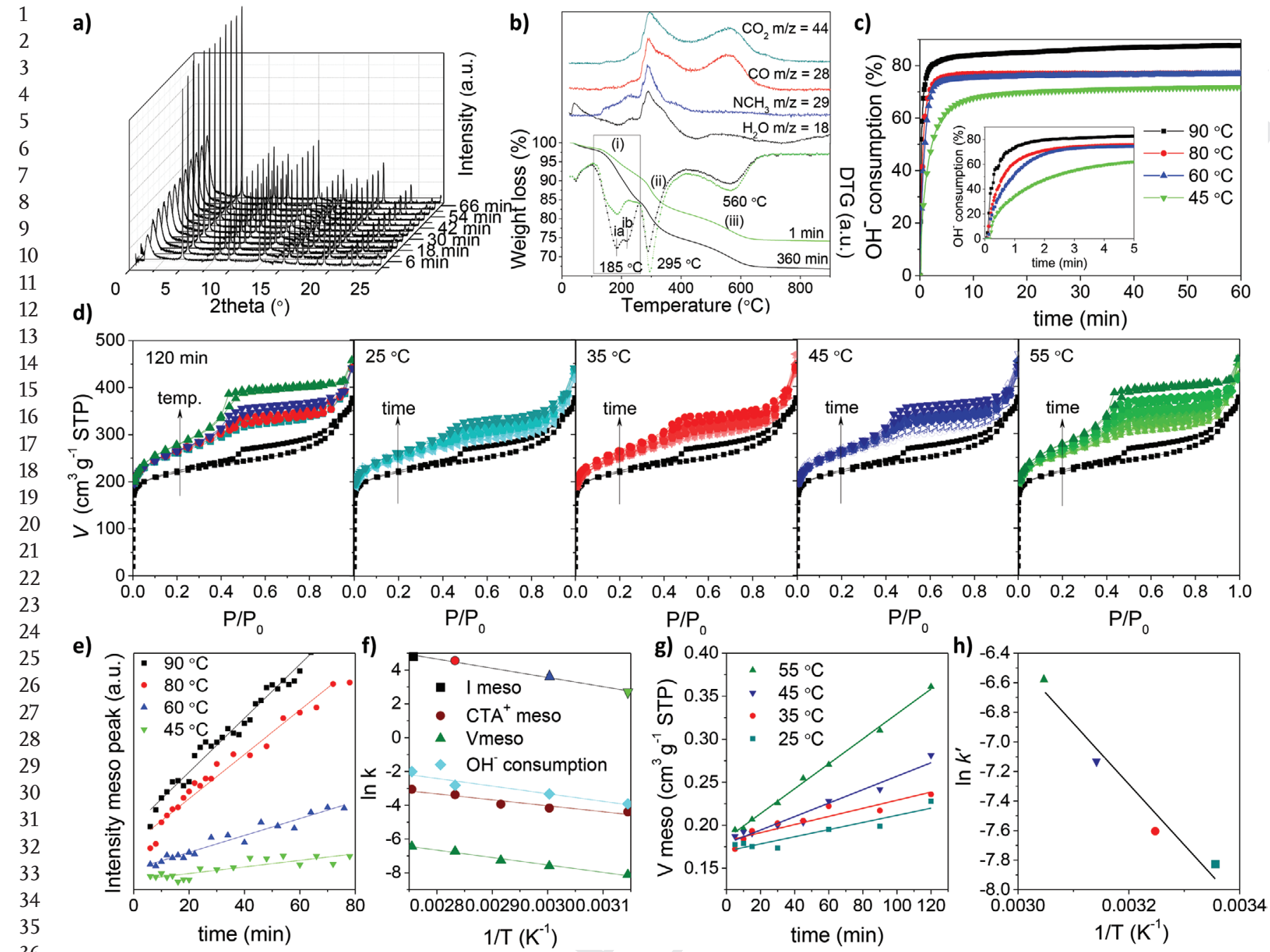

Figure 8. a-c) Evolution of the different parameters monitored during surfactant-templating of USY zeolite (Si/Al = 15): a) in situ time-resolved synchrotron XRD patterns at $90^{\circ} \mathrm{C}$. b) TG-DTG/MS measurements at the beginning $(1 \mathrm{~min})$ and the end $\left(360\right.$ min) of the treatment at $90{ }^{\circ} \mathrm{C}$ - the thermogravimetric analysis (TCA; solid line) is presented below along with the DTG data (dashed line); above are plotted various molecular species recorded from the MS measurements and their evolution with temperature. c) $\mathrm{OH}^{-}$consumption profiles at different temperatures. d) $\mathrm{N}_{2}$ adsorption/desorption isotherms at $77 \mathrm{~K}$ during surfactant-templating of USY zeolite $(\mathrm{Si} / \mathrm{Al}=40)$ at different temperatures and after 120 min of treatment. e) Intensity profiles of the peak at $1.682 \theta$ (mesoporosity) during surfactant-templating of USY zeolite $(\mathrm{Si} / \mathrm{Al}=15)$ at different temperatures. $\mathrm{f})$ Arrhenius plots obtained from the evolution of the different parameters associated to the development of mesoporosity in a surfactant-templated USY zeolite $(\mathrm{Si} / \mathrm{Al}=15)$ at $90^{\circ} \mathrm{C}(0.09 \mathrm{M} \mathrm{NaOH})$. g) Mesopore volume evolution during surfactant-templating of USY zeolite $(\mathrm{Si} / \mathrm{Al}=40)$ at different temperatures. h) The derived Arrhenius plot of the system shown in (g). Adapted with permission. ${ }^{[22,25]}$ Copyright 2018 and 2019, Wiley- $\mathrm{VCH}$.

temperatures evaluated. The cleavage of $\mathrm{Si}-\mathrm{O}-\mathrm{Si}$ bonds took place during the first $5 \mathrm{~min}$ of the treatment (Figure 8c) presenting a significant apparent activation energy $\left(\mathrm{Ea}^{\mathrm{OH}-}=35 \mathrm{~kJ}\right.$ $\mathrm{mol}^{-1}$; Figure $8 \mathrm{f}$, light blue line). On the other hand, the second step was evaluated by determining the amount of $\mathrm{CTA}^{+}$responsible for the mesopores formation by TG-MS (Figure 8b). The incorporation of $\mathrm{CTA}^{+}$inside the zeolite is an electrostatically driven process which presents the lowest apparent activation energy, $\mathrm{Ea}^{\mathrm{CTA}+}=29 \mathrm{~kJ} \mathrm{~mol}^{-1}$ (Figure 8f, dark red line), as it is the least impeded step. ${ }^{[25]}$ The determination of the kinetic parameters involved in the surfactant-templating process provided a deeper understanding of this approach and shed new light on its possible mechanism.
Later on, Linares et al. ${ }^{[22]}$ extended this analysis to zeolites with a lower amount of aluminum in their framework such as the $\mathrm{CBV} 780(\mathrm{Si} / \mathrm{Al}=40) . \mathrm{N}_{2}$ physisorption experiments were carried out to materials treated at different temperatures, as shown in Figure 8d. Similarly to what we observed in the case of CBV 720, the mesopore volume grew linearly with the time of treatment during the initial moments of the process (Figure 8g). Following the same approach, these values were used to calculate the rate constants, $k^{\prime}$, and from them, the Arrhenius plot shown in Figure 8h. The apparent activation energy of the development of mesoporosity in CBV 780 was found to be $\mathrm{Ea}^{\mathrm{Vmeso}}=34 \mathrm{~kJ} \mathrm{~mol}^{-1},{ }^{[22]}$ a lower value than the one estimated for CBV 720 ${ }^{[25]}\left(\mathrm{Ea}^{\text {Vmeso }}=43 \mathrm{~kJ} \mathrm{~mol}^{-1}\right)$. This difference 

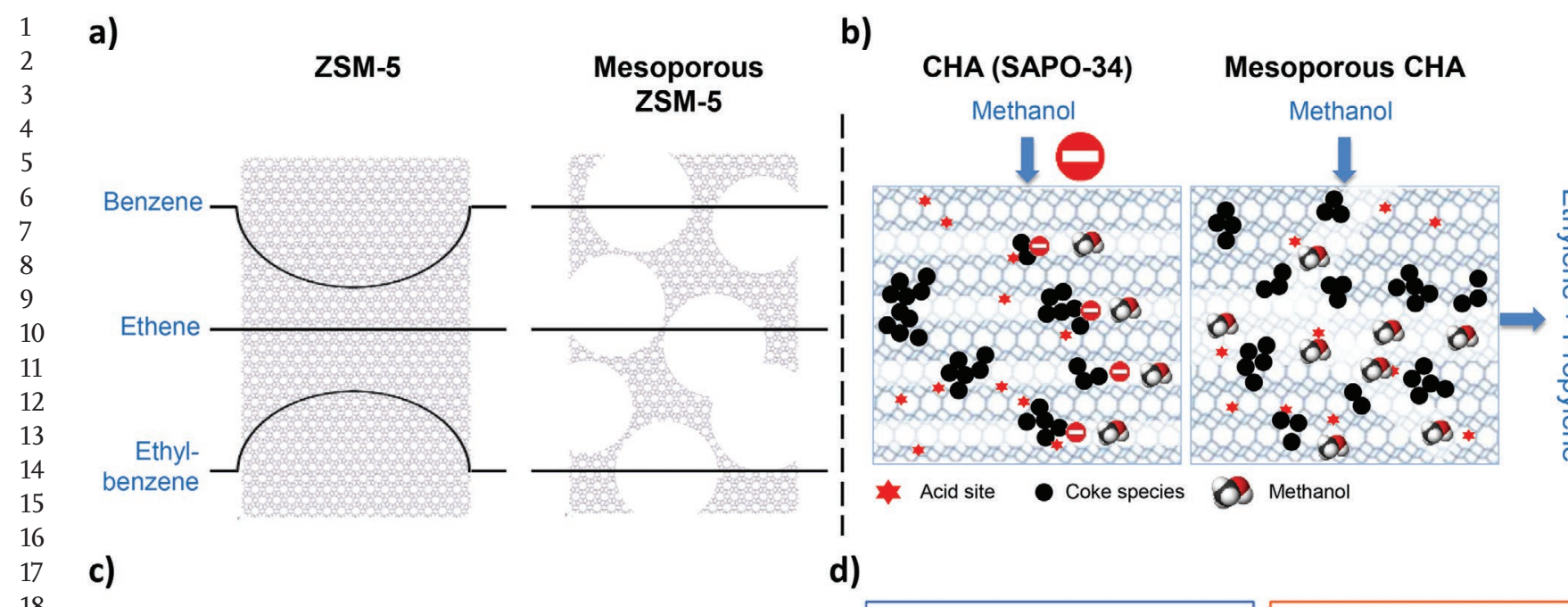

d)
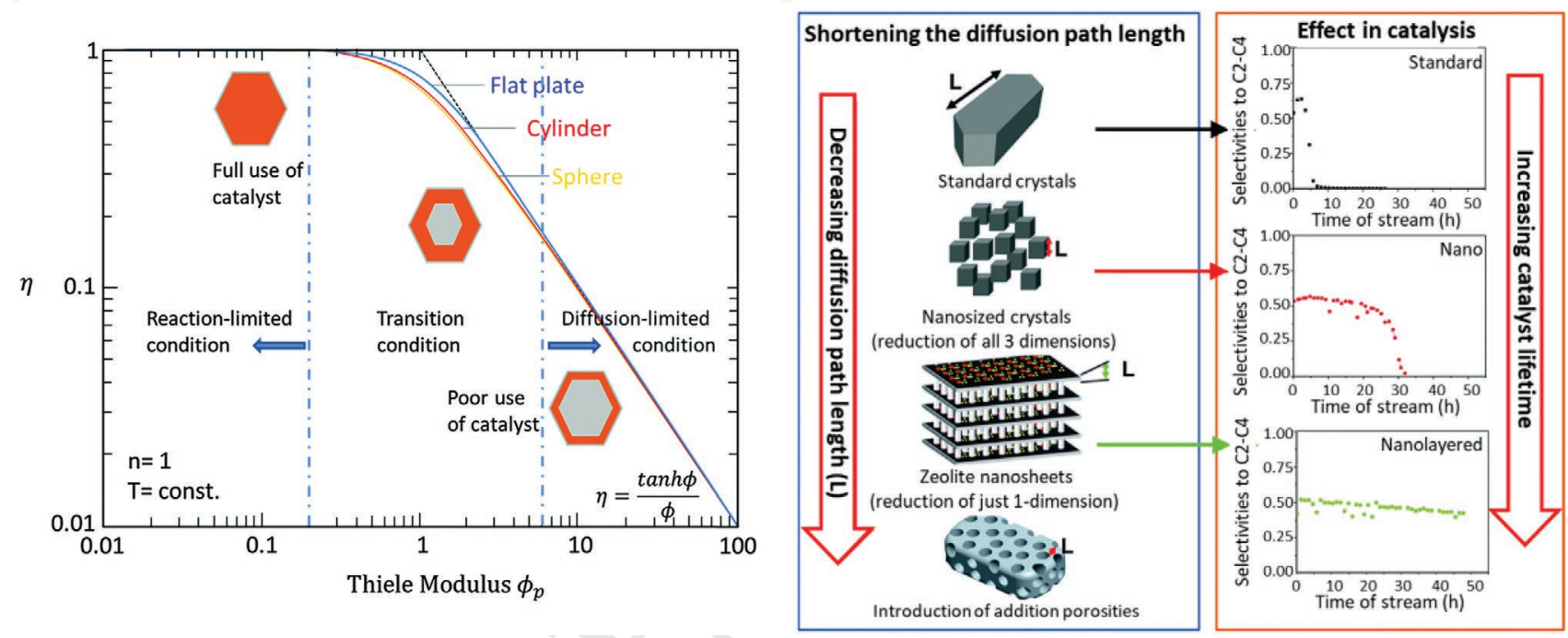

Figure 9. Diffusion path length and catalytic performance of hierarchical zeolites (prepared by different methods) as compared to their microporous zeolite: a) schematic illustration of concentration profiles of reagents and products during the ethylation of benzene. Adapted with permission. ${ }^{[63]}$ Copyright 2008, Elsevier. b) Benefits of hierarchical porosity in SAPO-34 for the synthesis of ethylene and propylene via the methanol-to-olefine reaction. Adapted with permission. ${ }^{[3]}$ Copyright 2019, Elsevier. c) Effectiveness factor $(\eta)$ as a function of Thiele modulus $(\phi)$ for different geometries. d) Summary of the influence of the reduced diffusion path length. On the left side, the different strategies used to reduce the diffusion path lengths are visualized, and the impacts of different diffusion path lengths in catalysis are displayed on the right side. Reproduced with permission. ${ }^{[2]}$ Copyright 2016, Royal Society of Chemistry.

can be attributed to the lower aluminum content in the former, which results in a less stable zeolite framework under basic $\mathrm{pH}$. Consequently, the easy cleavage of the $\mathrm{Si}-\mathrm{O}-\mathrm{Si}$ bonds in CBV 780 under the treatment conditions favors the transformation of the zeolite during the mesostructuring process. ${ }^{[18]}$

\section{Surfactant-Templated Zeolites in Catalysis}

\subsection{Hierarchical Zeolites in Catalysis: General Considerations}

Zeolites are widely used as catalysts in industry. ${ }^{[53-56]}$ More specifically, they are the most important heterogeneous catalysts in petrochemisty. They are the main component of the catalysts used in the most important refining processes, including FCC, hydrocracking, alkylation, isomerization, and reforming, just to cite a few. ${ }^{[57,58]}$ Zeolite Y replaced clay-based catalysts in FCC 44 more than 50 years ago. ${ }^{[59,60]}$ The low cost associated with this 45 material and its special properties: i) strong Brønsted acidity, 46 ii) excellent thermal and hydrothermal stability, and iii) high 47 surface area and relatively large pores, are some of the reasons 48 for the widespread use of this catalyst. ${ }^{[60]}$ However, the presence 49 of microporosity in the zeolites imposes significant limitations 50 for the access and molecular transport of reagents and prod- 51 ucts, which can negatively impact their catalytic performance, 52 both activity and selectivity, as well as the lifetime of these cata- 53 lysts. ${ }^{[43,61]}$ As an example, Figure 9a (left) depicts the concentra- 54 tion profiles of reagents and products in a zeolite crystal during 55 the ethylation reaction of benzene with ZSM-5. Both benzene 56 and ethylbenzene present important diffusion limitations in 57 this process. ${ }^{[62]}$ The restriction in the molecular mobility of 58 those compounds inside the crystals increases their time of 59 
residence in the zeolite, which enhances the probability of side reactions. Thus, the long diffusion paths occurring in microporous zeolites may favor overconversion of the products into undesired side products and the formation of coke. ${ }^{[2]}$ The accumulation of coke in the micropores can block the access to the active sites and, as a result, the zeolite deactivates (Figure 9b, left). Hierarchical zeolites (prepared by different methods) have emerged as a solution to these drawbacks as the incorporation of larger pores enhances the diffusion through the crystal. ${ }^{[2]}$ The mobility of molecules in mesoporous zeolites is not restricted, as is shown in Figure 9a (right). As a consequence, both the improved access of the reactants to the active sites and the exit of the products outside the zeolite crystal during the reaction cycle $^{[63]}$ enhance the performance of the zeolite and delay its pore blocking, which also extends the lifetime of the catalyst, see, e.g., Figure $9 b$ right. ${ }^{[3]}$

In this context, the incorporation of pores of appropriate size in the zeolite crystals is critically important to enhance their utilization as industrial catalysts, which is one of the most studied topics in reaction engineering. ${ }^{[61]}$ The degree of catalyst utilization is described by the effectiveness factor $(\eta)$, which relates the real reaction rate with the intrinsic chemical rate ( $\left.\eta=r_{\text {obs }} / r_{\text {intrinsic }}\right)$. The plot of the effectiveness factor against the Thiele modulus $(\phi)$ provides relevant information about the path length, the rate constant, and the diffusion coefficient. ${ }^{[2,61]}$ As a general trend, only a percentage of the catalyst is used for large values of $\phi$. For instance, for the particulate catalyst shown in Figure 9c, a $\eta$ lower than 0.7 is found at $\phi>1$, which means that less than $70 \%$ of the catalyst is actually used because the system is under diffusion-limited conditions. On the contrary, small path lengths resulted in a low $\phi$, indicating that most of the catalyst particle was effectively used. In fact, when $(\phi \rightarrow 0)$ and $(\eta \rightarrow 1)$, the observed rate equals the intrinsic reaction rate and the system operates under reaction limited conditions, which is the case of hierarchical zeolites. ${ }^{[2,61]}$ In addition, and as abovementioned, the improved diffusion in the zeolite crystals due to the presence of mesopores positively impacts not only their usage but also their lifetime. ${ }^{[62]}$ On this note, Figure $9 \mathrm{~d}$ shows an increase in the lifetime of the catalysts when the path length is shortened by the reduction of the crystal dimensions or introduction of a secondary network of pores (macro-meso) into the zeolite framework. ${ }^{[2]}$

\subsection{Catalysis with Surfactant-Templated Zeolites}

\subsubsection{Fluid Catalytic Cracking}

In 2006, Ying and Garcia-Martinez founded Rive Technology Inc., a spin-off company from MIT created to study, scale up, and commercialize surfactant-templated zeolites. ${ }^{[16]}$ They reported a seminal series of papers on the synthesis, characterization, and catalytic testing of these materials. ${ }^{[33,43]}$ The catalytic evaluation of a mesostructured USY zeolite prepared from a commercial $\mathrm{NH}_{4} \mathrm{Y}$ zeolite (Zeolyst CBV 300, $\mathrm{Si} / \mathrm{Al}=2.6$ ) was carried out by using different standard methods for testing FCC catalysts. ${ }^{[33,43]}$ The mesostructuring of the aluminum-rich FAU zeolite was performed using a mild acid pretreatment, as detailed in Section 2.3 and refs. ${ }^{[18,33]}$. Subsequently, a basic treatment with surfactants was performed at $80{ }^{\circ} \mathrm{C}$ for $24 \mathrm{~h} \quad 1$ (see the isotherms and XRD patterns in Figure 10a,b, black and 2 blue lines). The mesostructured Y zeolite was then converted to mesostructured USY by using a typical ultrastabilization step (Figure 10a,b, green lines). Finally, this material was deactivated by steaming at $788^{\circ} \mathrm{C}$ in pure steam for $4 \mathrm{~h}$ (Figure 10a,b, red lines). Both a decrease in the microporous volume and a broadening of the mesopore size distribution was observed after these severe hydrothermal treatment steps; however, the steam-deactivated zeolite retained $\approx 63 \%$ of the micropores volume, which is similar to the value observed for conventional zeolite Y, and most of its mesopore volume. ${ }^{[3]}$ Initially, the mesostructured zeolite was tested as powder in the catalytic cracking of a VGO, using a microactivity test unit (MAT). Its efficiency was evaluated in comparison with the microporous USY zeolite, obtaining more gasoline and diesel (transportation fuels, the most valuable fractions) and a reduction in the coke and gases formed in the former. ${ }^{[33]}$ Encouraged by these promising results, the scalability of the process was tested and multikilogram quantities were successfully obtained using industrial equipment. These zeolites showed excellent properties and were consequently formulated as FCC microspheres and deactivated as mentioned above. For comparison purposes, the original (nonmesoporous) zeolite was treated using the same procedure. Both catalysts were evaluated in a fluidized bed ACE testing unit with different feedstocks (see Figure 10c-e). Similarly to what happened with the powders (MAT testing), the mesostructured FCC catalysts (Figure 10c-e, dashed lines) produced significantly more gasoline and light cycle oil (LCO), and fewer bottoms and coke (undesired products) than the conventional FCC catalyst, which contained microporous USY zeolite (Figure 10c-e, solid lines). These differences were even higher when heavier VGO feedstocks were used instead. ${ }^{23,33,62]}$ Bulkier hydrocarbons benefit more from the presence of mesoporosity in zeolite, yielding better results when processing heavier feedstocks, ${ }^{[23,33,62]}$ which are ever increasingly more frequent. ${ }^{[60]}$ One of the challenges that have been listed for FCC catalysis in the last years is to fully maximize LCO. Taking into account the outstanding catalytic activity and stability of the surfactant-templated zeolite, this is a target in which the mesostructured zeolite can definitely help with. ${ }^{[60]}$

Shortly after these initial evaluations, the mesotructured FCC catalysts were successfully scaled up to a tonnage level (30 tons). These materials, which were produced safely and costeffectively, presented excellent properties. Subsequently, they were tested in an ACE and pilot plant DCR (Davison Circulating Riser), yielding similar catalytic results to the laboratory experiments. ${ }^{[43]}$ The mesotructured FCC catalysts also showed excellent hydrothermal stability in a commercial trial in the FCC unit of the Along Big Spring refinery, in Texas (USA) ${ }^{[43]}$ Figure 10f-h summarizes the results of the 2012 trial at Alon's Big Spring (Texas). ${ }^{[11]}$ In detail, the mesostructured catalysts produced: i) higher gasoline and diesel yields (LCO); ii) increased production of valuable light olefins (propylene and butenes); and iii) lower amount of coke (see Table 2 and Figure 10f-h). Furthermore, the economic uplift obtained by the refinery by simply replacing the old FCC catalyst by the Rive Technology new FCC catalyst was estimated to be over $\$ 2.50$ per bbl, which clearly facilitates its widespread application. ${ }^{[64]}$ Owing to 2 3 4 5 6 7 
a)

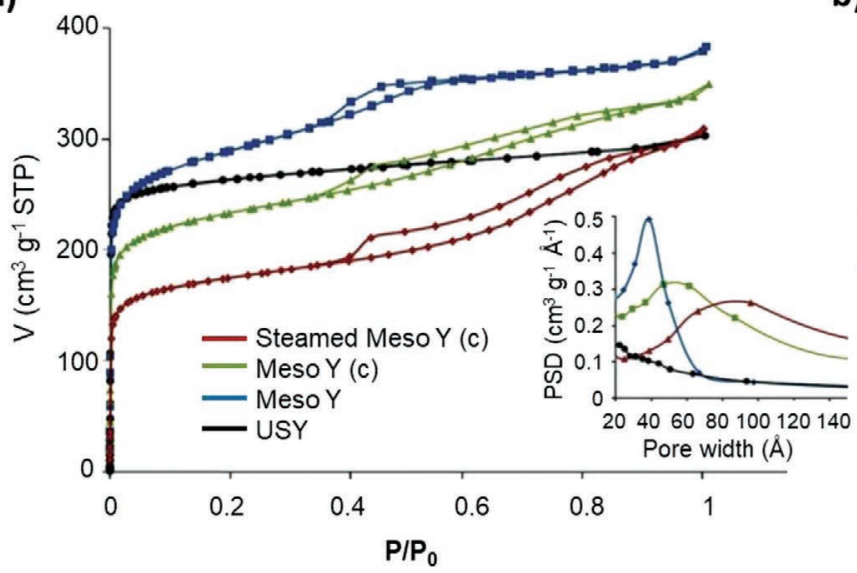

c)

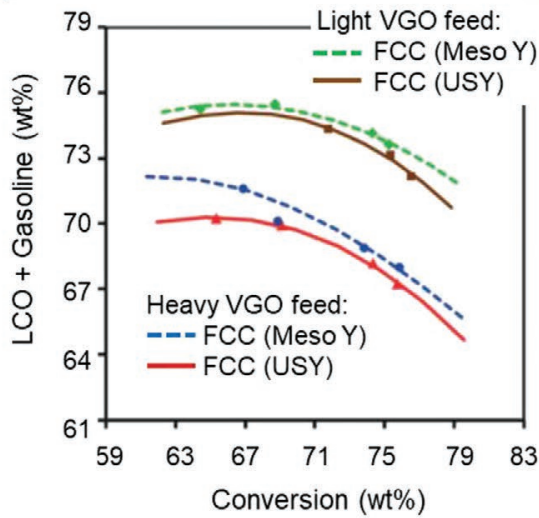

f)

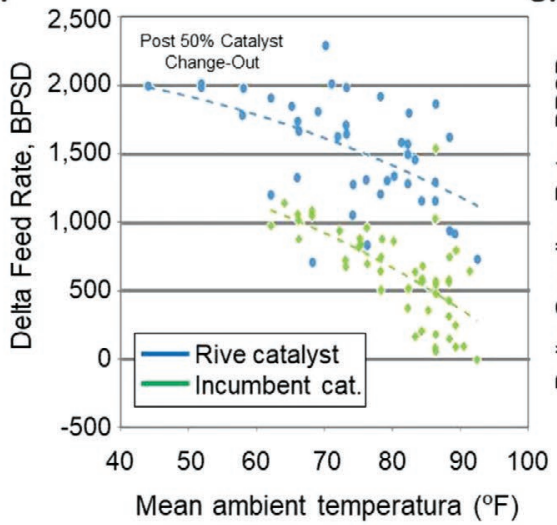

d)

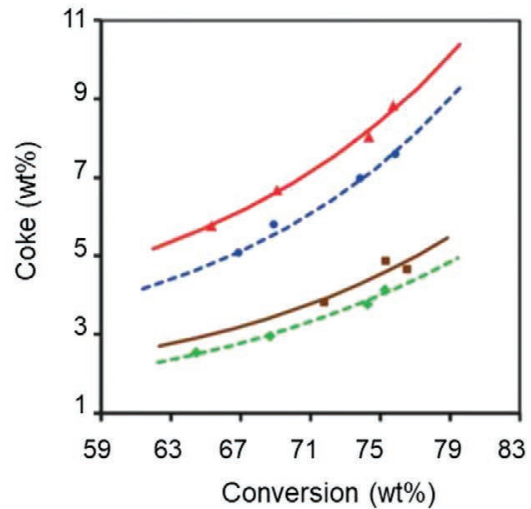

b) 1

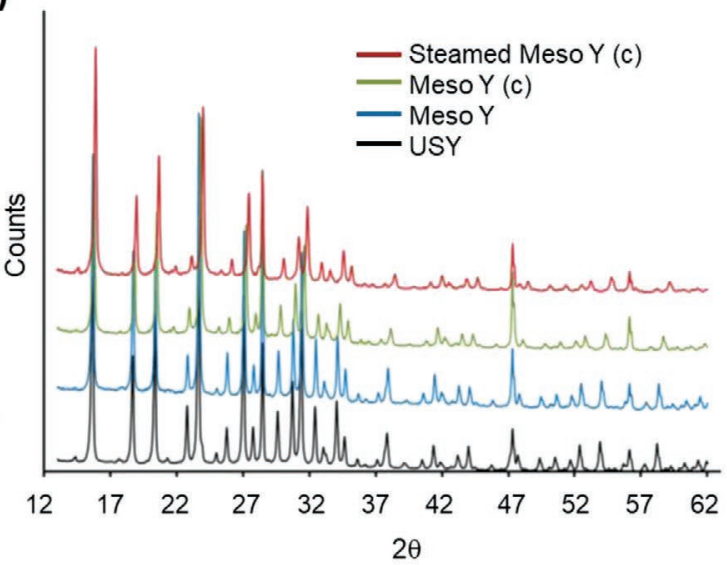

e)

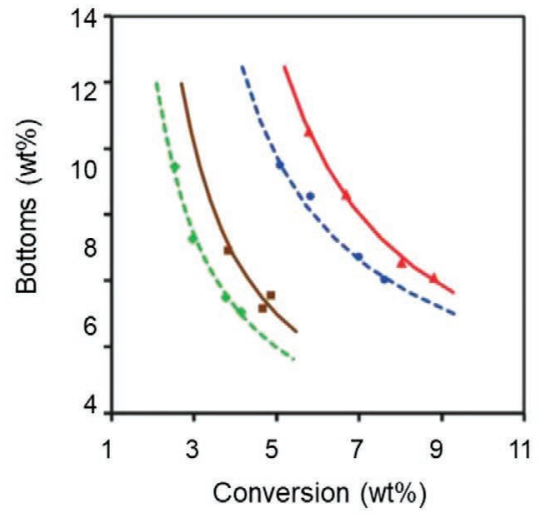

h)

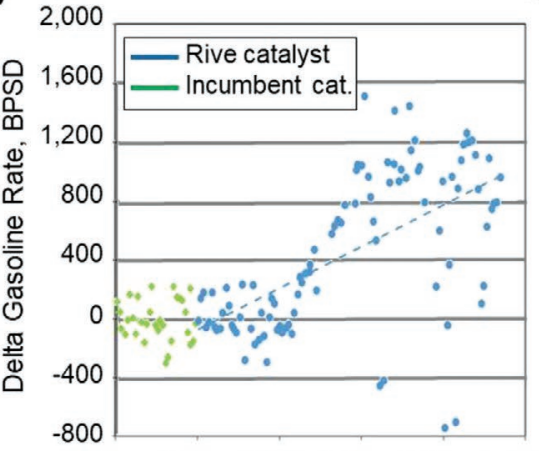

31May 30Jun 30Jul 29Aug 28Sept 280ct Year 2012

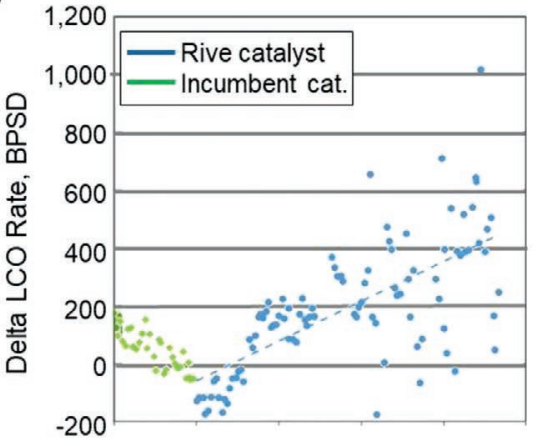

31May 30Jun 30Jul 29Aug 28Sept 280ct Year 2012

Figure 10. a) $\mathrm{N}_{2}$ adsorption/desorption isotherms at $77 \mathrm{~K}$ and b) $\mathrm{XRD}$ patterns of a $\mathrm{NH}_{4}-\mathrm{Y}$ zeolite (black circle), the mesostructured $\mathrm{Y}$ (blue square), and the mesostructured USY before (green triangle) and after (red diamond) deactivation at $788{ }^{\circ} \mathrm{C}$ in $100 \%$ steam for $4 \mathrm{~h}$. The corresponding BJH pore size distributions of these samples are shown in the inset of panel (a). Adapted with permission. ${ }^{[33]}$ Copyright 2012, Royal Society of Chemistry. c-e) Advanced cracking evaluation (ACE) testing results comparing two catalysts containing mesostructured USY zeolite to two state-of-the-art cata- 5 lysts with conventional USY using two different North American refinery feeds: light VGO feed-Meso Y (green symbols) and USY (brown squares), and heavy VGO feed-Meso Y (blue circles) and USY (red triangles), all curves were fitted by kinetic lump modeling: c) LCO + gasoline yields versus conversion. d) Coke yields versus conversion. e) Bottoms yields versus coke yields. $f-h$ ) Observed trends during a trial at Alon's Big Spring, Texas refinery: f) Increased feed rate by 700 BPSD (barrel per stream day). Increased production of g) gasoline and h) LCO (the big spikes in the plant data were owing to process interruptions and not to the catalyst) of the incumbent catalyst (green) and the Rive's MH-1 catalyst that contained mesostructured Y zeolite (blue). Reproduced with permission. ${ }^{[1]}$ Copyright 2014, Wiley.

the above features, in 2013, Rive Technology started the commercialization of a FCC catalyst containing the mesoporous Y zeolite prepared by the surfactant-templating method by the commercial name of Molecular Highway; which represents 57 the first industrial and large-scale application of hierarchical 58 zeolites. This story had a happy ending in 2019, when Rive 59 
Table 2. Refinery main product yields at constant conversion for the incumbent catalysts and the Rive one ( $\mathrm{MH}-1)$ containing the mesostructured Y zeolite. Along Big Spring, Texas, USA 2012. Reproduced with permission. ${ }^{[1]}$ Copyright 2014, Wiley.

\begin{tabular}{lcc}
\hline Catalyst & Incumbent catalyst & Rive catalyst (MH-1) \\
\hline C/O ratio & 6.2 & 6.4 \\
Conversion [wt\%] & 75 & 75 \\
Yield [wt\%] & & \\
Dry gas & 3.37 & 3.19 \\
Liquefied petroleum gas & 15.64 & 15.94 \\
Propane & 0.83 & 0.83 \\
Propylene & 4.67 & 4.77 \\
Butanes & 3.85 & 3.95 \\
Butenes & 6.29 & 6.39 \\
Gasoline & 50.39 & 51.33 \\
LCO & 19.09 & 19.15 \\
Bottoms & 5.91 & 5.86 \\
Coke & 5.60 & 4.54 \\
\hline
\end{tabular}

Technology Inc. was acquired by W. R. Grace \& Co., which is one of the leading worldwide FCC catalyst producers. ${ }^{[60]}$ There are few examples of such a significant industrial success like the commercialization of surfactant-templated zeolites for the most important refining process and their sale to one of the main catalyst supplier companies.

\subsubsection{Synthesis of Active Pharmaceutical Intermediates}

Recently, the catalytic applications of these hierarchical zeolites have been extended to fine-chemistry applications. In 2019, Linares et al. ${ }^{[35]}$ explored the use of the mesostructured USY zeolite for the production of two related active pharmaceutical ingredients (APIs), namely, $\mathrm{C}-\mathrm{H}$ functionalized indoles and steroids. These APIs are typically obtained through $\mathrm{C}-\mathrm{C}$ bond formation, i.e., alkylations and aldol condensations reactions, by using homogeneous catalysts (see Figure 11 (left)). ${ }^{[65,66]}$ Indole scaffolds are widely used for the treatment of neuropathic pain, glaucoma, migraine headaches or Alzheimer's and Parkinson's diseases, among others; ${ }^{[67]}$ whereas steroid analogs have many applications because of their effects on sex hormones, immune response, cell proliferation, and their neuroactive properties. ${ }^{[68]}$ Although zeolites are widely used to acid catalyze both alkylation and aldol condensation reactions, the large size of the pharmaceutical intermediates hinders their application in drug synthesis.

Because of these reasons, hierarchical USY zeolites, featuring a secondary mesoporous system, were tested as catalysts for the Friedel-Crafts alkylation of indole with benzoin and the Aldol condensation of estrone and benzaldehyde. The reactions were carried out under solvent-free conditions and intermediate temperatures, $\approx 100{ }^{\circ} \mathrm{C}$, obtaining excellent performances. Turnover frequencies (TOFs, calculated as the initial reaction rate per mole of acid site) $\approx 2$ to 40 times higher than that in the original zeolite were found (see Figure 11a,b). The bulkiness of the reagents and products determined the enhancement in their 1 performance. For instance, the alkylation of the indole with 2 the bulky alcohol benzoin ( $\alpha$-hydroxy- $\alpha$-phenylacetophenone) 3 generated the bulkiest derivative and, subsequently, the per- 4 formance of the mesoporous zeolite was the highest, showing 5 an enhancement of $\approx 40$ times in TOF related to the micropo- 6 rous USY zeolite (Figure 11a). The impact of the size of the reactants on the performance of both zeolites was further evidenced when the bulky compounds (benzoin and estrone) were replaced by other molecules with analogous functionalities, but that do not present steric limitations, namely, 3,4-dimethoxybenzyl alcohol for the Friedel-Crafts alkylation of indole, and cyclopentanone in the aldol condensation with benzaldehyde. Similarly to what was observed for other mesoporous zeolites, ${ }^{[69]}$ the performance was found to be comparable for small reactants, which do not experience diffusion limitations in the microporous zeolite. Indeed, the ratio between the TOF values of mesostructured and nonmesostructured zeolites approaches one in these systems (see Figure 11b, green area). However, if the critical diameter ${ }^{[0]}$ of the compound is similar/larger than the pore size of the zeolite (i.e., $d_{\text {crit }}=0.76 \mathrm{~nm}$ for benzoin versus $0.74 \mathrm{~nm}$ for the pore opening of FAU), striking differences in the activity of both catalysts could be observed and the hierarchical material greatly exceeds the activity of the microporous zeolite (see Figure $11 \mathrm{~b}$, red area).

Furthermore, not only the activity but also the stability of the catalyst was higher for the hierarchical material as compared to its microporous homologue (Figure 11c). As abovementioned, pore-blocking is a common cause of catalyst deactivation during the reaction, which results in a reduction in their catalytic activity during consecutive catalytic cycles. ${ }^{\left[{ }^{[1,72]}\right.}$ As observed in Figure 11c, the conversion of the mesoporous zeolite is preserved over successive catalytic cycles. More specifically, the surfactant-templated zeolite preserves $\approx 82 \%$ of its initial activity after 3 cycles whereas the conventional zeolite only retains $66 \%$ of its initial activity. The shorter diffusional path lengths found on the hierarchical catalysts allows better desorption of the products outside the zeolite micropores which, consequently, decreased the formation of undesired secondary reactions and increased its lifetime. ${ }^{[73]}$ This points out the excellent activity and stability of surfactant-templated USY zeolites in the conversion of bulky molecules under the tested conditions.

\subsubsection{Catalysis with Surfactant-Templated Zeolites other than FAU}

The evaluation of other surfactant-templated zeolite structures in catalysis has also proven an enhancement of the performance for these hierarchical materials. Al-Ani et al. ${ }^{[28,30]}$ applied mesostructured USY (FAU), beta (BEA), ZSM-5 (MFI), mordenite (MOR), and zeolite L (LTL) to the catalytic dealkylation of 1,3,5-tri-isopropylbenzene (TIPB), as a reaction test. ${ }^{[28]}$ In a subsequent publication, the same authors evaluated those structures for the esterification of oleic acid and the aldol condensation of furfural with acetone reactions. ${ }^{[30]}$ As shown in Table 3, most of the catalysts presented better results when the mesoporous zeolite is used. In the catalytic cracking of the bulky TIPB, first column of Table 3, all the hierarchical zeolites showed better conversions, related to more accessibility 5 6 7 8 9 10 11 12 13 14 15 16 17 18 19 20 21 22 23 24 25 26 27 28 29 30 31 32 


\section{Previous works:}

\section{Glucagon receptor antagonist}

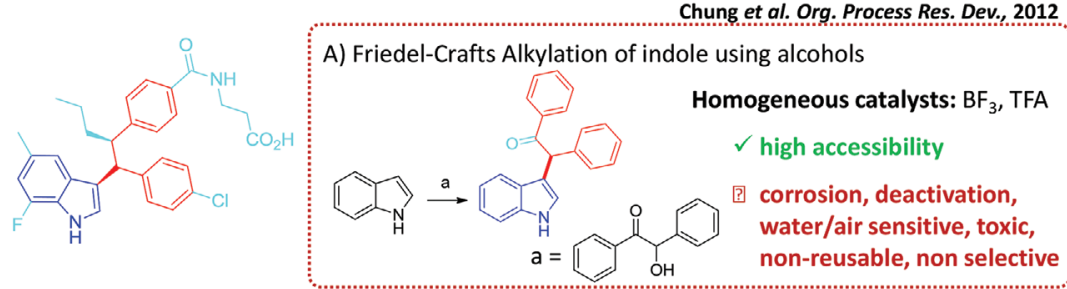

Leukemia cells inhibitor
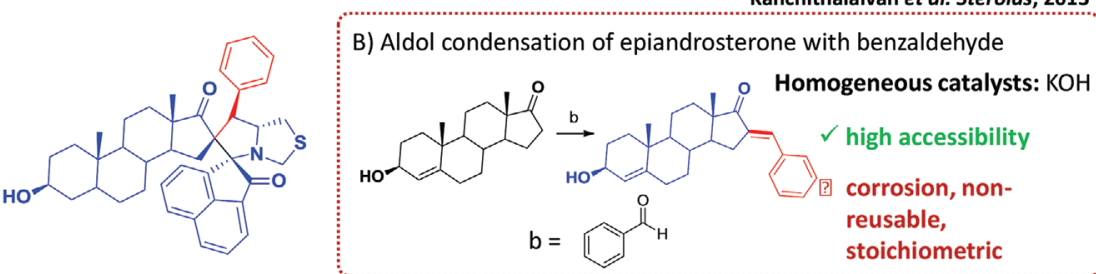

This work:

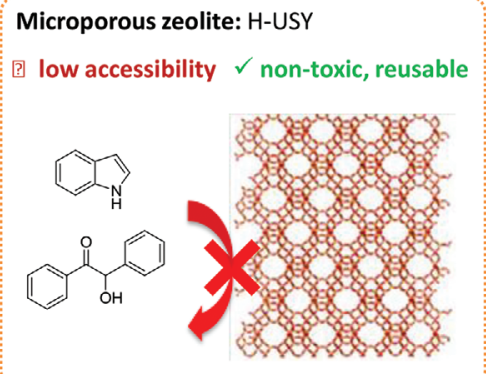

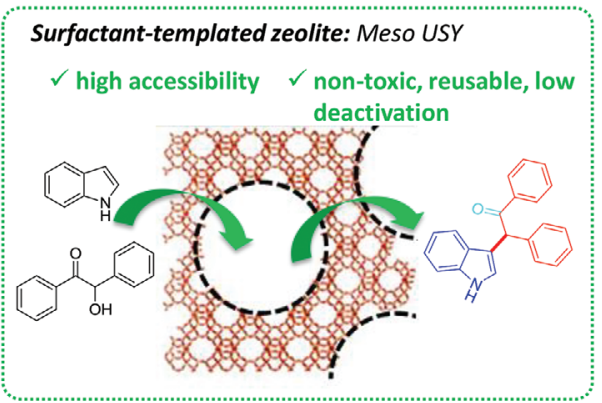

a)

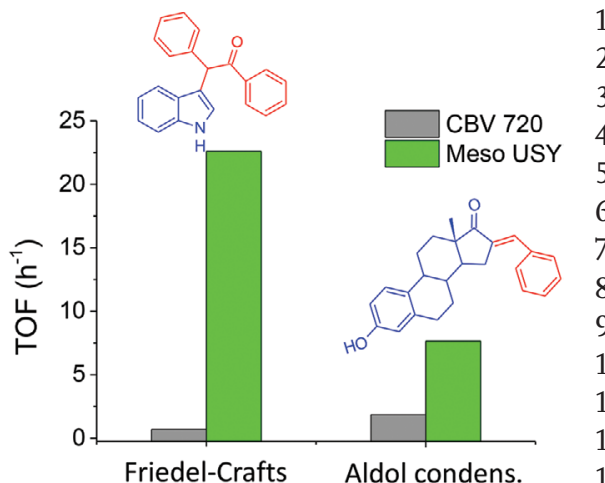

b)
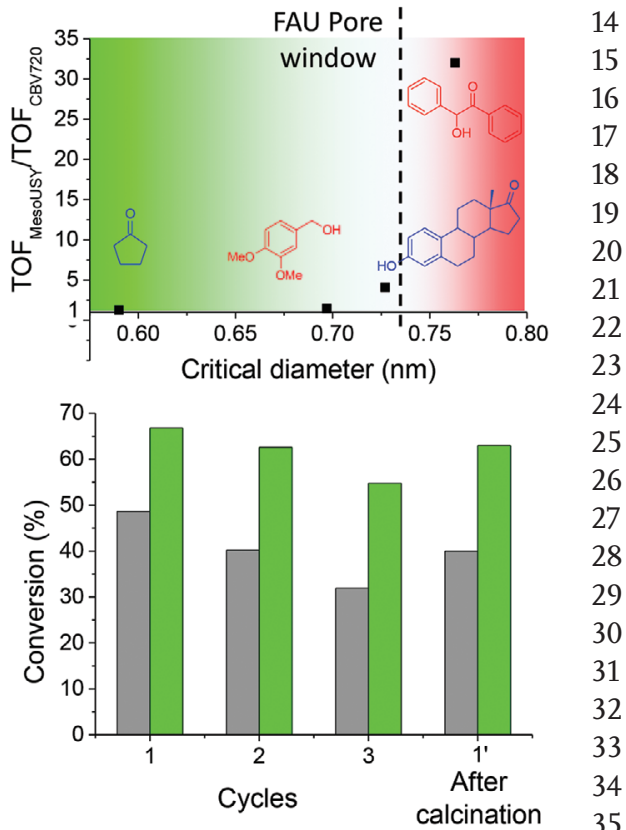

Figure 11. (Left) Reported preparation of APIs involving the Friedel-Crafts alkylation of indole using alcohols as alkylating agents, and aldol condensa- 36 tion of ketones with benzaldehyde reactions. a) (Right) Activity of conventional H-USY and Meso USY in the Friedel-Crafts alkylation of indole with 37 benzoin and in the Aldol condensation of estrone and benzaldehyde. b) Ratio between the activity of the hierarchical and microporous zeolites versus 38 the critical diameter of the reactants involved in the different reactions. c) Conversion over the microporous and hierarchical zeolites during 3 catalytic 39 cycles in the aldol condensation of estrone and benzaldehyde, and after calcination of both catalysts. Reproduced by permission. ${ }^{[35]}$ Copyright 2019 , Royal Society of Chemistry.

of the molecule to the active sites of the zeolite. Moreover, the selectivity of the reaction to the di-isopropylbenzene products drastically increased, see ref. [28], which points out the shortened diffusion paths for the bulky molecules in the surfactanttemplated zeolites. On the other hand, a limited improvement was found in the esterification of oleic acid when the same zeolites were employed as catalysts (second column of Table 3). In this reaction, the strength of the Brönsted acid sites (BAS) determines the catalytic performance. The strong BAS present in the original beta and ZSM-5 zeolites are already enough to reach near $100 \%$ conversion in $60 \mathrm{~min}$, whether the microporous or the mesoporous zeolites are used. When zeolites with milder acid sites are employed (FAU, LTL), the tuning of the textural properties can result in better catalytic results, as it is the case for the surfactant-templated FAU. Finally, in the aldol condensation of furfural with acetone, third column of Table 3, all the hierarchical zeolites yielded higher furfural conversion and selectivity to the target product (FAc, Furfural acetone) 43 than the original microporous zeolites. The selectivity to FAc 44 could be further increased up to almost $100 \%$ by incorporating 45 basic sites into the zeolites; this is, by using their K-exchanged 46 version.

As mentioned in Section 2.4, Talebian-Kiakalaieh and Tarighi 48 reported a modified surfactant-templated method that resulted 49 in a highly mesoporous MFI zeolite. ${ }^{[46]}$ The integration of this 50 material in a FCC catalyst together with a surfactant-templated 51 USY (prepared from a NaY as reported in Section 2.3) yielded 52 enhanced catalytic results for the conversion of VGO to value- 53 added chemicals. When comparing with catalysts prepared 54 either by a combination of microporous zeolites or by including 55 only one mesostructured zeolite, the highest gasoline yield was 56 produced over the catalyst containing the hierarchical zeolites, 57 which reach a $50 \%$ yield of gasoline at almost $100 \%$ of conver- 58 sion. Indeed, the mesoporous structure of zeolites successfully 59 
1 Table 3. Catalytic performance in different reactions for the original zeo2 lites and the corresponding surfactant-templated version. Column 1, Repro3 duced with permission. ${ }^{283}$ Copyright 2019, Royal Society of Chemistry.

5 6 7 8

Columns 2 and 3, Adapted with permission. ${ }^{[30]}$ Copyright 2020, Elsevier.

\begin{tabular}{lccc}
\hline Catalyst & $\begin{array}{c}\text { TIPB } \\
\text { conversion [\%] }\end{array}$ & $\begin{array}{c}\text { Oleic acid } \\
\text { conversion [\%] }\end{array}$ & $\begin{array}{c}\text { Furfural } \\
\text { conversion [\%] }\end{array}$ \\
\hline Y & 35 & 65 & 41 \\
Meso-Y & 54 & 90 & 70 \\
Beta & 12 & 95 & 76 \\
Meso-beta & 17 & 95 & 88 \\
ZSM-5 & 2 & 95 & 40 \\
Meso-ZSM-5 & 6 & 95 & 51 \\
Mordenite & 2 & 70 & 48 \\
Meso-mordenite & 9 & 72 & 77 \\
L & 1 & 27 & 10 \\
Meso-L & 13 & 27 & 12 \\
\hline
\end{tabular}

enhanced the interaction between the catalyst active sites and the bulky molecules of feedstock (VGO) increasing the yield of not only gasoline, but also propylene, and olefins. Moreover, this (micro/meso) catalyst reported the lowest levels of undesired products, including alkanes and dry gas. The authors compared those results with some previous studies in the field, obtaining one of the highest gasoline yields with their surfactant-templated based FCC catalyst.

\section{Applications beyond Catalysis}

One of the main applications that have been explored for surfactant-templated zeolites beyond catalysis is the adsorptive removal of sulfur compounds from transportation fuels, a research that has been pioneered by the group of J. Valla. ${ }^{[31,32,34]}$ Using zeolites as sorbents for desulfurization is a very promising approach as it requires low energy levels and has low associated costs; however, the diffusion limitations imposed by the micropore structure of the zeolites can reduce their adsorption capacity and, consequently, their applicability. Furthermore, the selective adsorption of only the sulfur compounds from a mixture of hydrocarbons is a difficult task. In 2017, Lee and Valla ${ }^{[31]}$ demonstrated that the use of surfactant-templated Y zeolites ion-exchanged with $\mathrm{Ce}$ and/or $\mathrm{Cu}$ overcame these drawbacks yielding very good results. The shorter diffusion path length of the mesoporous zeolite improved its adsorption capacity for sulfur compounds, as compared to the original one, while the incorporation of the metals created relatively stronger bonds, as well as the possibility of multiple adsorption configurations. Specifically, a mesoporous zeolite prepared from a $\mathrm{NH}_{4} \mathrm{Y}$ zeolite $(\mathrm{Si} / \mathrm{Al}$ ratio $\approx 2.4$ ) performed better than other mesoporous materials well-known as sorbents for desulfuration. This comparative study proved hierarchical zeolites very promising candidates for the removal of sulfur compounds. The success of this first work, which was based on the use of a model fuel such as $n$-octane, motivated the authors to perform subsequent studies by using a mixture of hydrocarbons, including aromatics. ${ }^{[34]}$ While the addition of benzene, naphtalene, or methyl-naphtalene to the mixture greatly reduced the adsorption 1 capacity of the original zeolite, the use of ion-exchanged bimetallic $(\mathrm{Cu}$ and $\mathrm{Ce})$ surfactant-templated zeolite overcame this challenge. More specifically, a high dibenzothiophene adsorption capacity was found for the bimetallic hierarchical zeolite in the presence of benzene. This value was even higher if naphtalane was present in the mixture, due to the synergistic effect of the presence of mesoporosity, which reduced diffusion limitations, and the ion-exchanged metals, which highly increased the selectivity toward sulfur compounds. Finally, the same authors have recently investigated the regeneration and lifetime of the spent sorbents to improve the sustainability of the process. ${ }^{[32]}$ Quite remarkably, the dibenzothiophene adsorption capacity of the mesoporous zeolite was totally recovered after a thermal treatment at $500{ }^{\circ} \mathrm{C}$. The hierarchical zeolite was used for 3 consecutive adsorptive cycles and, in all cases, 100\% adsorption capacity was achieved. The comparison with previous studies evidenced a longer desulfurization lifetime together with milder regeneration conditions which, consequently, foresees a great potential of the mesostructured zeolites for the desulfurization of commercial fuels. ${ }^{[32,74-76]}$ This is only one of the main possibilities that surfactant-templated zeolites offer beyond catalysis, including selective adsorption of bulky compounds, VOCs, air and water treatment, environmental protection, agriculture and smart delivery.

\section{Conclusions and Outlook}

Thanks to the effort made over the last decade, the scientific community has been able to reduce to the practice what until a few years ago seemed impossible; this is to produce a material combining the acidity and stability of a zeolite with the diffusion properties of surfactant-templated (amorphous) materials. Many techniques, both bottom-up and top-down, have been used to produce hierarchical zeolites in the last years, but the postsynthetic treatment with surfactants presents important advantages. Among them, the precise control over the mesoporosity introduced paved the way to their commercialization. We have built on three decades of knowledge in the use of surfactants to induce controlled intracrystalline mesoporosity in a variety of zeolites with tunable pore size and volume, and different architectures.

This technology has been extended by different research groups to the main zeolite structures in a broad range of $\mathrm{Si} / \mathrm{Al}$ ratios. This method allows for the preservation of the unique characteristics of zeolites (i.e., strong acidity, crystallinity, microporosity, and hydrothermal stability), even in those cases where a large amount of mesoporosity is introduced. Moreover, thanks to the contributions of other research groups, which independently studied and expanded our technology, the diffusion improvements produced by the incorporation of intracrystalline mesoporosity in zeolites was unambiguously confirmed for a number of systems.

Surfactant-templated zeolites have been thoroughly characterized by a large number of techniques, including multiple time-resolved approaches. In situ microscopy, both AFM and Liq-TEM, allowed us to directly observe the development of intracrystalline mesoporosity in zeolites and to provide the first visualization of the crystal reconstruction that occurs 2 3 4 5 6 7 
during surfactant-templating. The formation of intracrystalline mesoporosity during the treatment was also studied by in situ time-resolved synchrotron X-ray diffraction and small-angle scattering. The combination of these two in situ methods with more traditional ex situ characterization techniques, such as $\mathrm{pH}, \mathrm{TG}$, and nitrogen physisorption, allows for determining the activation energy of the development of mesoporosity in zeolites and of the different steps involved in the mesostructuring process. Quite remarkably, the apparent activation energy of the development of surfactant-templated mesoporosity was found to be very similar to that involved in the synthesis of zeolites, hence confirming that the incorporation of mesoporosity is energetically feasible under similar conditions of temperature, pressure, and time used in the crystallization of zeolites.

Regarding the thermochemistry of the surfactant-templating process, we managed to learn, using high-temperature oxide melt solution calorimetry, that the destabilization caused by the incorporation of mesoporosity in the zeolite $\left(\approx 2 \mathrm{~kJ} \mathrm{~mol}^{-1}\right)$ is lower than the stabilization energy due to the interaction between the surfactant and the zeolite framework (i.e., 6-12 kJ $\left.\mathrm{mol}^{-1}\right)$. This fact clearly evidences that surfactant-templating is a thermodynamically favored process with relatively low activation energy (30-50 kJ mol ${ }^{-1}$ ). Building on this knowledge, we were able to introduce intracrystalline mesoporosity in zeolite USY in just $1 \mathrm{~min}$ at $220^{\circ} \mathrm{C}$, using the ultrafast heating technique developed by Wakihara and co-workers.

Finally, the potential of the surfactant-templated zeolites as catalysts for different reactions of industrial interest, such as catalytic cracking as well as the synthesis of pharmaceutical intermediates, has been proved. Moreover, new avenues are being explored for these materials, such as on the adsorptive removal of sulfur compounds from transportation fuels.

Surfactant-templated zeolites are nowadays a commercial reality, being produced at thousands of tons per year scale, mainly for their use in the petrochemical industry, i.e., as an FCC component in various refineries around the world.

In little more than a decade, surfactant-templated zeolites went from an elusive goal into a commercial reality. There is still a lot to learn from this intriguing process that involves the reconstruction of the zeolite crystal to accommodate mesoporosity while maintaining its main characteristics, but the opportunities for these materials are countless.

\section{Acknowledgements}

Thanks are due to the European Commission for funding through the H2020-MSCA-RISE-2019 program (Ref. ZEOBIOCHEM - 872102), the Spanish MINECO and AEI/FEDER, UE through the projects ref. CTQ2015-74494-JIN and RTI2018-099504-B-C21, and the GV through the project ref. GRISOLIAP/2020/165. E.S. and N.L. also acknowledge the University of Alicante for funding (refs. UATALENTO16-03 and UATALENTO17-05, respectively).

\section{Conflict of Interest}

J.G.M. was co-founder of Rive Technology Inc. and currently consultant of W. R. Grace \& Co.

\section{Keywords}

catalysis enhancement, diffusional properties, hierarchical materials, 2 mesoporous zeolites, surfactant-templating

Received: August 6, 20205 Revised: October 13, 20206 Published online: 7

[1] J. García-Martínez, K. Li, Mesoporous Zeolites, Wiley-VCH, Weinheim, Germany 2015.

[2] M. Hartmann, A. G. Machoke, W. Schwieger, Chem. Soc. Rev. 2016, 45, 3313.

[3] R. Bai, Y. Song, Y. Li, J. Yu, Trends Chem. 2019, 1, 601.

[4] Q. Sun, Z. Xie, J. Yu, Natl. Sci. Rev. 2018, 5, 542.

[5] N. Masoumifard, R. Guillet-Nicolas, F. Kleitz, Adv. Mater. 2018, 30, 16 1704439.

[6] S. Mintova, J. P. Gilson, V. Valtchev, Nanoscale 2013, 5, 6693.

[7] J. Přech, P. Pizarro, D. P. Serrano, J. Áejka, Chem. Soc. Rev. 2018, 47, 19 8263.

[8] J. Čejka, R. Millini, M Opanasenko, D. P. Serrano, W. I. Roth, Catal. Today 2020, 345, 2.

[9] A. Sachse, J. García-Martínez, Chem. Mater. 2017, 29, 3827.

[10] J. Pérez-Ramírez, S. Abelló, A. Bonilla, J. C. Groen, Adv. Funct. Mater. 2009, 19, 164.

[11] K. Li, J. Valla, J. Garcia-Martinez, Chem CatChem 2014, 6, 46.

[12] L. H. Chen, X. Y. Li, J. C. Rooke, Y. H. Zhang, X. Y. Yang, Y. Tang, 26 F. S. Xiao, B. L. Su, J. Mater. Chem. 2012, 22, 17381.

[13] D. Verboekend, N. Nuttens, R. Locus, J. Van Aelst, P. Verolme, 28 J. C. Groen, J. Pérez-Ramírez, B. F. Sels, Chem. Soc. Rev. 2016, 45, 3331. 29

[14] D. Kerstens, B. Smeyers, J. Van Waeyenberg, Q. Zhang, J. Yu, 30 B. F. Sels, Adv. Mater. 2020, 2004690.

[15] L.-H. Chen, M.-H. Sun, Z. Wang, W. Yang, Z. Xie, B.-L. Su, Chem. Rev. 2020, https://doi.org/10.1021/acs.chemrev.0c00016.

[16] J. Y. Ying, J. Garcia-Martinez, US7589041B2, 2005.

[17] I. I. Ivanova, E. E. Knyazeva, Chem. Soc. Rev. 2013, 42, 3671.

[18] A. Sachse, A. Grau-Atienza, E. O. Jardim, N. Linares, M. Thommes, J. García-Martínez, Cryst. Growth Des. 2017, 17, 4289.

[19] C. T. Kresge, W. J. Roth, Chem. Soc. Rev. 2013, 42, 3663.

20] E. De Oliveira Jardim, E Serrano, J. C Martínez, N Linares, 38 J. García-Martínez, Cryst. Growth Des. 2020, 20, 515.

[21] A. N. Migues, S. Vaitheeswaran, S. M. Auerbach, J. Phys. Chem. C 40 2014, 118, 20283.

[22] N. Linares, E. De Oliveira Jardim, G. Sharma, E. Serrano, 41 A. Navrotsky, J. García-Martínez, Chem. - Eur. J. 2019, 25, 10045.

[23] J. Garcia-Martinez, C. Xiao, K. A. Cychosz, K. Li, W. Wan, X. Zou, M. Thommes, Chem CatChem 2014, 6, 3110.

[24] N. Linares, A. Sachse, E. Serrano, A. Grau-Atienza, E. De Oliveira Jardim, J. Silvestre-Albero, M. A. L. Cordeiro, F. Fauth, G. Beobide, O. Castillo, J. García-Martínez, Chem. Mater. 2016, 28, 8971.

[25] N. Linares, E. O. Jardim, A. Sachse, E. Serrano, J. García-Martínez, Angew. Chem., Int. Ed. 2018, 57, 8724.

[26] A. Galarneau, F. Guenneau, A. Gedeon, D. Mereib, J. Rodriguez, F. Fajula, B. Coasne, J. Phys. Chem. C 2016, 120, 1562.

[27] D. Mehlhorn, J. Rodriguez, T. Cacciaguerra, R. D. Andrei, C. Cammarano, F. Guenneau, A. Gedeon, B. Coasne, M. Thommes, D. Minoux, C. Aquino, J. P. Dath, F. Fajula, A. Galarneau, Langmuir 2018, 34, 11414.

[28] A. Al-Ani, J. J. C. Haslam, N. E. Mordvinova, O. I. Lebedev, A. Vicente, C. Fernandez, V. Zholobenko, Nanoscale Adv. 2019, 1, 2029.

[29] N. Suárez, J. Pérez-Pariente, F. Mondragón, A. Moreno, Microporous Mesoporous Mater. 2019, 280, 144.
Q11 
[30] A. Al-Ani, C. Freitas, V. Zholobenko, Microporous Mesoporous Mater. 2020, 293, 109805.

[31] K. X. Lee, J. A. Valla, Appl. Catal., B 2017, 201, 359.

[32] K. X. Lee, H. Wang, S. Karakalos, G. Tsilomelekis, J. A. Valla, Ind. Eng. Chem. Res. 2019, 58, 18301.

[33] J. García-Martínez, M. Johnson, J. Valla, K. Li, J. Y. Ying, Catal. Sci. Technol. 2012, 2, 987.

[34] K. X. Lee, G. Tsilomelekis, J. A. Valla, Appl. Catal., B 2018, 234, 130.

[35] N. Linares, F. G. Cirujano, D. E. De Vos, J. García-Martínez, Chem. Commun. 2019, 55, 12869.

[36] J. Kenvin, S. Mitchell, M. Sterling, R. Warringham, T. C. Keller, P. Crivelli, J. Jagiello, J. Pérez-Ramírez, Adv. Funct. Mater. 2016, 26, 5621.

[37] C. Peng, Z. Liu, Y. Yonezawa, N. Linares, Y. Yanaba, C. A. Trujillo, T. Okubo, T. Matsumoto, J. García-Martínez, T. Wakihara, J. Mater. Chem. A 2020, 8, 735.

[38] A. Chawla, N. Linares, J. D. Rimer, J. García-Martínez, Chem. Mater. 2019, 31, 5005

[39] M. Thommes, K. Kaneko, A. V. Neimark, J. P. Olivier, F. RodriguezReinoso, J. Rouquerol, K. S. W. Sing, Pure Appl. Chem. 2015, 87, 1051

[40] K. A. Cychosz, R. Guillet-Nicolas, J. García-Martínez, M. Thommes, Chem. Soc. Rev. 2017, 46, 389.

[41] Q. Huo, D. I. Margolese, G. D. Stucky, Chem. Mater. 1996, 8, 1147.

[42] W. Wan, J. Sun, J. Su, S. Hovmöller, X. Zou, J. Appl. Crystallogr. 2013, 46, 1863.

[43] J. García-Martínez, K. Li, G. Krishnaiah, Chem. Commun. 2012, 48, 11841.

[44] P. M. Piccione, C. Laberty, S. Yang, M. A. Camblor, A. Navrotsky, M. E. Davis, J. Phys. Chem. B 2000, 104, 10001.

[45] A. Navrotsky, O. Trofymluk, A. A. Levchenko, Chem. Rev. 2009, 109, 3885.

[46] A. Talebian-Kiakalaieh, S. Tarighi, J. Ind. Eng. Chem. 2020, 88, 167.

[47] D. Verboekend, G. Vilé, J. Pérez-Ramírez, Cryst. Growth Des. 2012, 12, 3123.

[48] I. Petrovic, A. Navrotsky, M. E. Davis, S. I. Zones, Chem. Mater. 1993, 5, 1805.

[49] E. C. Moloy, L. P. Davila, J. F. Shackelford, A. Navrotsky, Microporous Mesoporous Mater. 2002, 54, 1.

[50] O. Trofymluk, A. A. Levchenko, A. Navrotsky, Microporous Mesoporous Mater. 2012, 149, 119.

[51] H. Kacirek, H. Lechert, J. Phys. Chem. 1976, 80, 1291.

[52] J. C. Groen, G. M. Hamminga, J. A. Moulijn, J. Pérez-Ramírez, Phys. Chem. Chem. Phys. 2007, 9, 4822.

[53] A. Corma, Chem. Rev. 1997, 97, 2373.

[54] M. J. Climent, A. Corma, S. Iborra, Zeolites and Catalysis: Synthesis, Reactions and Applications, Wiley-VCH, Weinheim, Germany 2010, pp. 775-826.
[55] M. Dusselier, P. Van Wouwe, A. Dewaele, P. A. Jacobs, B. F. Sels, 1 Science 2015, 349, 78.

[56] T. Ennaert, J. Van Aelst, J. Dijkmans, R. De Clercq, W. Schutyser, M. Dusselier, D. Verboekend, B. F. Sels, Chem. Soc. Rev. 2016, 45, 584.

[57] Y. Li, L. Li, J. Yu, Chem 2017, 3, 928.

[58] B. Yilmaz, U. Müller, Top. Catal. 2009, 52, 888.

[59] A. Corma, Stud. Surf. Sci. Catal. 1989, 49, 49.

[60] E. T. C. Vogt, B. M. Weckhuysen, Chem. Soc. Rev. 2015, 44, 7342.

[61] J. Pérez-Ramírez, C. H. Christensen, K. Egeblad, C. H. Christensen, J. C. Groen, Chem. Soc. Rev. 2008, 37, 2530.

[62] M. S. Holm, E. Taarning, K. Egeblad, C. H. Christensen, Catal. Today 2011, 168, 3.

[63] C. H. Christensen, K. Johannsen, E. Törnqvist, I. Schmidt, H. Topsøe, C. H. Christensen, Catal. Today 2007, 128, 117.

[64] G. Krishnaiah, B. Speronello, A. Hansen, J. Crosby, in AFPM Annual Meeting 2013, American Fuel and Petrochemical Manufacturers, Washington 2013, pp. 17-31.

[65] J. Y. L. Chung, D. Steinhuebel, S. W. Krska, F. W. Hartner, C. Cai, J. Rosen, D. E. Mancheno, T. Pei, L. DiMichele, R. G. Ball, C. Y. Chen, L. Tan, A. D. Alorati, S. E. Brewer, J. P. Scott, Org. Process Res. Dev. 2012, 16, 1832

[66] S. Kanchithalaivan, R. R. Kumar, S. Perumal, Steroids 2013, 78, 409.

[67] F. G. Cirujano, E. López-Maya, M. Rodríguez-Albelo, E. Barea, J. A. R. Navarro, D. E. De Vos, ChemCatChem 2017, 9, 4019.

[68] F. G. Cirujano, I. Luz, M. Soukri, C. Van Goethem, I. F. J. Vankelecom, M. Lail, D. E. De Vos, Angew. Chem., Int. Ed. 2017, 56, 13302.

[69] T. C. Keller, S. Isabettini, D. Verboekend, E. G. Rodrigues, J. PérezRamírez, Chem. Sci. 2014, 5, 677.

[70] C. O. Kowenje, E. T. Osewe, Advanced Catalytic Materials, John Wiley \& Sons, Inc., Hoboken, NJ 2015, pp. 411-438.

[71] M. D. Argyle, C. H. Bartholomew, Catalysts 2015, 5, 145.

[72] E. Heracleous, E. Pachatouridou, A. M. Hernández-Giménez, H. Hernando, T. Fakin, A. L. Paioni, M. Baldus, D. P. Serrano, P. C. A. Bruijnincx, B. M. Weckhuysen, A. A. Lappas, J. Catal. 2019, $380,108$.

[73] L. Lakiss, F. Ngoye, C. Canaff, S. Laforge, Y. Pouilloux, Z. Qin M. Tarighi, K. Thomas, V. Valtchev, A. Vicente, L. Pinard, J.-P. Gilson, C. Fernandez, J. Catal. 2015, 328, 165.

[74] A. J. Hernández-Maldonado, R. T. Yang, W. Cannella, Ind. Eng. Chem. Res. 2004, 43, 6142.

[75] A. J. Hernández-Maldonado, R. T. Yang, Ind. Eng. Chem. Res. 2004, 43, 1081.

[76] L. Wang, B. Sun, F. H. Yang, R. T. Yang, Chem. Eng. Sci. 2012, 73, 208.

\section{2}

3 


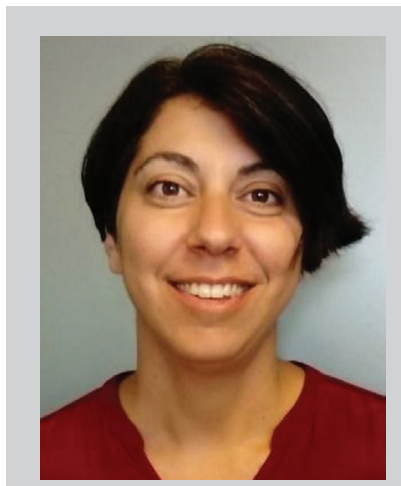

Noemi Linares received her Ph.D. in Materials Science in 2010 from the University of Alicante (UA, Spain). After a postdoc in the Istituto di Chimica dei Composti Organometallici (Florence), she is currently a senior researcher at the Molecular Nanotechnology Lab of the Inorganic Chemistry Department of the UA. Noemi Linares' current research interests are focused on: i) the preparation and characterization of novel hierarchical materials and their application in catalytic processes, and ii) the control of the morphology in photoactive inorganic semiconductors for their use in photocatalytic processes.

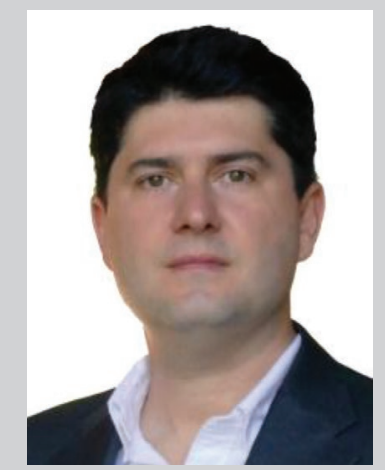

Javier Garcia-Martinez is a professor of Inorganic Chemistry and the director of the Molecular Nanotechnology Laboratory of the University of Alicante (UA, Spain). His current research interests are on nanoporous materials and their application to the energy sector. Javier is the vice-chair of the World Economic Forum General Assembly Council on Emerging Technologies, a member of the Global Young Academy, and a fellow of the RSC. Since 2019, he has been a president-elect (president for the biennium 2022-2024 period) of the IUPAC. He is also a cofounder of Rive Technology, Inc. (Boston, MA), an MIT spin-off commercializing hierarchical zeolites for diffusionlimited applications, acquired by W. R. GRACE in 2019. 